\title{
A Low-Cost and Highly Efficient Method of Reducing Coolant Leakage for Direct Metal Printed Injection mold with Cooling Channels Using Optimum Heat Treatment Process Procedures
}

Chil-Chyuan Kuo ( $\nabla$ jacksonk@mail.mcut.edu.tw)

Ming Chi University of Technology https://orcid.org/0000-0003-0519-4126

Shao-Xuan Qiu

Ming Chi University of Technology

Xin-Yi Yang

Ming Chi University of Technology

\section{Research Article}

Keywords: Metal additive manufacturing, Injection molding tools, Heat treatment, Coolant leakage, Cooling channel

Posted Date: March 18th, 2021

DOI: https://doi.org/10.21203/rs.3.rs-321108/v1

License: (c) (1) This work is licensed under a Creative Commons Attribution 4.0 International License.

Read Full License 


\section{Abstract}

Metal additive manufacturing (MAM) provides lots of benefits and potentials in manufacturing molds or dies with sophisticated conformal cooling channels. It is known that the conformal cooling technology provides effective cooling to reduce cycle time for increasing productivity. Ordinarily, mold inserts fabricated by general printing procedures will result in coolant leakage in the injection molding process. The yield in the manufacturing of fully dense injection molding tools was limited to the very narrow working widow. In addition, high costs of fully dense injection mold fabricated by MAM constitute the major obstacle to its application in the mold or die industry. In general, the high cost of MAM is approximately $50-70 \%$ more expensive than conventional computer numerical control machining. In this study, a low-cost and highly efficient method of reducing coolant leakage for direct metal printed injection mold with cooling channels was proposed. This new method employs general process parameters to manufacture the green injection mold rapidly and then uses optimum heat treatment (HT) procedures to improve microstructure of the green injection mold. The results of this study revealed that optimum HT procedures can prevent coolant leakage and save manufacturing time of the injection mold fabricated by direct metal laser sintering. The evolution mechanisms of microstructure were investigated experimentally. The save in the injection mold manufacture time about $67 \%$ can be obtained.

\section{Introduction}

In the industry, the productivity is a key issue for large-volume production since it is closely related to the cooling time of the injection molded parts. To decrease the cooling time, the conformal cooling channel (CCC) [1] was employed in the molds or dies. Some additive manufacturing (AM) technologies [2, 3], including fused deposition modeling, direct metal laser sintering (DMLS), vacuum diffusion bonding, selective laser sintering, selective laser melting or selective electron beam melting were widely employed to manufacture physical models, microchannels[4], molds or dies. DMLS process can fabricate injection mold with shape and internal structure using a continuous wave fiber laser to sinter metal powders according to a computer-aided design file. Some distinct properties such as heat dissipation rate, stiffness-to-weight ratio, or energy absorption capability can be obtained by the cellular structures inside the molds, dies, or metal components produced with DMLS process to solve challenging industrial problems. Attarzadeh et al. [5] did the research to correlate the DMLS process procedures with the surface roughness of components produced with DMLS. It was found that achieving a minimum line roughness at a reasonable fractional density is approximately equivalent to achieving the maximum fractional density. Contaldi et al. [6] carried out experiments to investigate the effect of powder reuse for two kinds of precipitation hardening stainless steel. Results showed the knowledge about the effect of powder reuse with regard to stainless steels, demonstrating the possibility to reuse excess metal powder in powder bed fusion processes. It was found that no significant variation was observed in terms of mechanical properties ascribable to powder reuse. Kundu et al. [7] fabricated titanium nitride reinforced Ti6Al4V alloy based metal matrix composites under an argon atmosphere using fiber laser. It was found that the microhardness measured by Vickers test was improved from 388 to $590 \mathrm{HV}$ with an increase in 
the volume percentage of TiN. AlMangour et al. [8] conducted the experiments to investigate the deformation behavior of 17 - 4 precipitate hardenable stainless steel produced by direct metal laser sintering using micropillar compression and transmission electron microscopy. It was found that the microstructures and properties of $17-4$ stainless steel specimens fabricated by DMLS vary significantly from those of specimens produced by conventional methods. Alafaghani et al. [9] investigated the effect of manufacturing procedures on the microstructure and mechanical properties of metal laser sintering parts of precipitate hardenable metals. It was found that 15-5PH and IN718 produced using DMLS can be used in applications with elevated environmental temperatures, as there was no observable permeant change in the microstructure. Mazzarisi et al. [10] proposed a phenomenological model for forecasting three main process parameters: laser power, powder feed rate, and translation speed and suggested the best ranges of the process parameter exponents for establishing the most suitable combined parameters to predict geometric characteristics of the clad. It was found that new formulations are in good agreement with the behaviors defined in the literature.

Metal additive manufacturing (MAM) [11] has drawn much attention since it can manufacture molds, dies, or functional components rapidly for design evaluation. In general, an injection mold fabricated by general process parameters will result in coolant leakage in the injection molding process. However, fabrication of a high-density injection mold with CCCs is a time-consuming process. According to practical experience, the success rate of using DMLS process to produce high-density injection molding molds with complex CCC is relatively low since the process control during the DMLS process needs to be manipulated carefully. In the preliminary study, the failed direct metal printed injection molds are shown in the Fig. 1. The total number of slicing layers of the injection mold with CCC is 560 . The fist case is that the roller collides the sintered agglomerates appeared on the surface of the injection mold when the injection mold with CCC was printed to 439 layers. This collision activates the safety device and the machine was stopped immediately, resulting in the injection mold making failure. The second case is that the sintered agglomerates on the roller collides with the injection mold surface and scratches when the injection mold with CCC was printed to 97 layers. This collision also activates the safety device and the machine was stopped immediately, resulting in the injection mold making failure. According the practical experiences, two disadvantages were found when a high-density injection mold with CCC was fabricated by DMLS. First, it is a time-consuming process. Second, the success rate is relatively low. Therefore, the development of a high-yield process for producing high-density injection molding molds with complex CCC is an important research issue. In this study, a cost-effective method of reducing coolant leakage for injection mold produced with DMLS was proposed. The injection mold with CCC was produced by general process procedures to reduce the failure rate and the injection mold was processed with the post-heat treatment $(\mathrm{HT})$ to increase both the densification and mechanical properties for reducing coolant leakage during injection molding process. The cooling time of the injection molded part, transit mold temperature history, transit part temperature history, and warpage of the injection molded part were numerically examined using the molding simulation software. The recrystallization mechanism of reducing coolant leakage for direct metal printed injection mold with CCC was proposed. 


\section{Experiment}

The three-dimensional computer-aided design (CAD) models of part and CCC were imported from an Creo parametric 3D modeling software to Moldex3D simulation software (R14 SP30R, CoreTech System Inc.) via a data exchange STEP format for investigating the cooling time of the injection molded part, transit mold temperature history, transit part temperature history, and warpage of the injection molded part. The process procedures for the simulation include the filling time of $2 \mathrm{~s}$, injection pressure of $0.06 \mathrm{MPa}$, mold temperature of $25^{\circ} \mathrm{C}$, melt temperature of $99^{\circ} \mathrm{C}$, room temperature of $22^{\circ} \mathrm{C}$, coolant temperatures of 25 ${ }^{\circ} \mathrm{C}$, coolant flow rate of $130 \mathrm{cc} / \mathrm{s}$, and an ejection temperature of $30^{\circ} \mathrm{C}$. As can be seen in Figure 2 , there are three key aspects to be addressed. This study focuses mainly on the optimum HT process procedures. The injection mold with CCC was designed and fabricated to evaluate the amount of water leakage during cooling stage. The test specimens of HT were designed and fabricated to investigate the optimum HT process procedures for fabricating the injection mold with CC. The optimum HT process procedures were proposed based on both mechanical properties and the amount of coolant leakage. Finally, the recrystallization mechanism of reducing coolant leakage was proposed. In this study, the maraging stainless steel (MSS) powder (LaserForm Inc.) was used to fabricate injection molds using a DMLS technology (ProX 100, 3D System Inc.), which equips with an optical-path transmission system, a scanning galvanometer mirror, a Q-switched ytterbium doped yttrium aluminum garnet (Yb:YAG) $50 \mathrm{~W}$ fiber laser $(\lambda=1070 \mathrm{~nm})$, and a f-theta lens. The system has a building volume of $100 \mathrm{~mm} \times 100 \mathrm{~mm} \times$ $80 \mathrm{~mm}$. Figure 3 shows the field-emission scanning electron microscopy (FE-SEM) (JEC3000-FC, JEOL Inc.) and EDS (scanning electron microscopy) (D8 ADVANCE, Bruker Inc.) images of the MSS powder. The chemical compositions of MSS powder involve $62.51 \% \mathrm{Fe}, 16.27 \% \mathrm{Ni}, 11.75 \% \mathrm{Co}$, and $4.61 \% \mathrm{Mo}$. The average powder particle size is approximately $13 \mu \mathrm{m}$. The injection mold with CCC was produced by general process parameters including hatching space of $100 \mu \mathrm{m}$, layer thickness of $50 \mu \mathrm{m}$, laser power of $40 \mathrm{~W}$, and scanning speed of $240 \mathrm{~mm} / \mathrm{s}$. The microstructures of the test specimen before and after HT were examined by FE-SEM and XRD. The process parameters for fabricating high densification injection mold include hatching space of $60 \mu \mathrm{m}$, layer thickness of $30 \mu \mathrm{m}$, laser power of $50 \mathrm{~W}$, and scanning speed of $200 \mathrm{~mm} / \mathrm{s}$.

Figure 4 shows the CAD model and dimensions of the heat treatment test specimen. The test piece is cylindrical with a diameter and height of $20 \mathrm{~mm}$. Figure 5 shows the CAD model and dimensions of the test mold with CC. The length, width, and height of the mold are $28 \mathrm{~mm}, 26 \mathrm{~mm}$ and $16 \mathrm{~mm}$, respectively. The diameter of the CC is $4 \mathrm{~mm}$. Figure 6 shows the CAD model and dimensions of the injection molded product. The injection molded product is a pipe cap used in investment casting. The outer diameter, height and thickness of the wax pattern are $23 \mathrm{~mm}, 15 \mathrm{~mm}$, and $1 \mathrm{~mm}$ respectively. Figure 7 shows the CAD model and dimensions of the injection mold with CCC. The length, width and height of the core insert are $62 \mathrm{~mm}, 62 \mathrm{~mm}$, and $31 \mathrm{~mm}$, respectively. The length, width and height of the cavity insert are $62 \mathrm{~mm}, 62 \mathrm{~mm}$, and $27 \mathrm{~mm}$, respectively. The diameter of the CC is $4 \mathrm{~mm}$ and the center distance with respect to mold cavity is $6 \mathrm{~mm}$. 
In this study, the wax (K512, Kato Inc.) was used as molding materials to fabricate wax patterns through a low-pressure wax injection molding machine (0660, W\&W Inc.). The characteristics of the molding material are depicted in the Figure 8 . The low-pressure injection molding process parameters involve injection pressure of $0.06 \mathrm{MPa}$ and wax melting temperature of $99^{\circ} \mathrm{C}$. To evaluate the cooling performance of the injection mold with and without CCC, a system composed of a temperature controller [12] (JCM-33A, Shinko Inc.) and a thermo-electric cooler (TEC12706AJ, Caijia Inc.) and a temperature controller (JCM-33A, Shinko Inc.), and three k-type thermocouples [13] (C071009-079, Cheng Tay Inc.) was developed. Figure 9 shows the experimental setup for investigating the cooling performance of the injection mold with and without CCC. The inlet coolant temperature was kept at room temperature. The thermocouples were placed in the wax injection molds for on-line monitoring the temperature history of the wax patterns. In-mold process data was collected using a data acquisition system (MRD-8002L, IDEA System Inc.). This data included continuous time-based data from thermocouples. Data was recorded at a sampling rate of one sample per second. To investigate the surface hardness of the test specimens after different $\mathrm{HT}$ procedures, the Vickers hardness tester was used in this study. The number of samples for the surface hardness of each test specimens is 50 . Five data of the maximum value and the minimum value are removed. The average surface hardness of the test specimens was calculated based on the remaining 40 data.

\section{Results And Discussion}

The 3D simulation models were firstly imported from CAD software to the simulation software through a data exchanges STEP format. The 3D solid mesh involves four different kinds of meshes, including prism, tetra, pyramid, and hexahedron. The number of nodes for tetra, pyramid, and hexahedron are 4, 5, and 6, respectively. In this study, the simulation models are composed of meshed with pyramid, tetrahedron, and hexahedron. Figure 10 shows the mesh sections of the injection mold, conformal cooling channels, and injection molded parts. To ensure accuracy of simulation results, the boundary layer mesh (BLM) was used in this study since it is suitable for simulation models with complex geometries. The higher the number of meshes denotes the longer the computing time of the simulation. In particular, the cooling time of the injection molded part reaches the steady state when the mesh element counts of exceeding 400,000. Thus, the mesh element count of 400,000 seems to be the optimal number of meshes based on both the correctness of the cooling time and the computing time of the simulation. The simulation model include injection molded part, CCC, mold base, and runner. The number of elements and nodes are $53,018,68,008,261,604$, and 8,000 , respectively. The total elements and nodes are approximately 39,0630 . The average edge length is about $0.4 \mathrm{~mm}$.

In the injection molding simulation, the melt front time (MFT) result showed the position of melt front with respect to time during the filling stage. Optimization of MFT provides the balanced flow contribution of each gate. The wax injection molding process includes three stages: filling, cooling, and ejection stage. Figure 11 shows the simulation results of the filling of the molded part at the end of filling (EOF). The filling time of the molded part is approximately $2 \mathrm{~s}$. In the injection molding simulation, the average part temperature results showed the distribution of temperature on the front face of part at the end of cooling 
(EOC). Figure 12 shows the numerical simulation results of the part temperature difference at the EOC for the injection mold with and without CCC. The results revealed that the part temperature at the same location of the molded parts fabricated by the injection mold with CCC can be lower than $2{ }^{\circ} \mathrm{C}$ compared to that for the injection mold without CCC. In the injection molding simulation, the magnitudes of deformations in three directions in each position inside the wax patterns can be estimated. Figure 13 shows the numerical simulation results of the $x$-displacement, $y$-displacement, $z$-displacement, and totaldisplacement of the molded part for the injection mold with and without CCC. The x-displacement, $y$ displacement, z-displacement, and total-displacement of the molded part for the injection mold without CCC are -0.049-0.049 mm,-0.023-0.035 mm, -0.049-0.049 mm, and 0.017-0.06 mm, respectively. The $x-$ displacement, y-displacement, z-displacement, and total-displacement of the molded part for the injection mold with CCC are -0.033-0.033 mm, -0.014-0.023 mm, -0.033-0.033 mm, and 0.01-0.04 mm, respectively. As can be seen, $\mathrm{x}$-displacement, $\mathrm{y}$-displacement, z-displacement, and total-displacement of the molded part for the injection mold with CCC are lower than those of the injection mold without CCC.

The cooling time can be estimated from end of packing (EOP) to the instant that wax pattern temperature has been cooled down to the ejection temperature. Figure 14 shows the numerical simulation results of the cooling time of the molded part for the injection mold with and without CCC at the EOP. The theoretical cooling times of the molded part for the injection mold with and without CCC are $13 \mathrm{~s}$ and 18 $\mathrm{s}$, respectively. It should be noted that about $27.7 \%$ improvement in the cooling time of the molded part can be obtained when the designed CCC was embedded in the injection mold.

In this study, a series of HT experiments were conducted on the MSS samples. In general, HT experiments involve three categories: solution treatment (ST), direct aging treatment (DAT), and solution \& aging treatment (SAT). According to the literature reviews, the temperatures of $\mathrm{ST}$ include $780{ }^{\circ} \mathrm{C}, 840{ }^{\circ} \mathrm{C}, 900$ ${ }^{\circ} \mathrm{C}, 960{ }^{\circ} \mathrm{C}$ or $1020^{\circ} \mathrm{C}$ and the duration is $0.25,0.5,1,2$ or 4 hours. The temperature of DAT is $400{ }^{\circ} \mathrm{C}$, $440{ }^{\circ} \mathrm{C}, 480^{\circ} \mathrm{C}, 520^{\circ} \mathrm{C}$ or $560{ }^{\circ} \mathrm{C}$ and the duration is $1,3,6,9$ or $12 \mathrm{~h}$. The general SAT HT procedures are at $900{ }^{\circ} \mathrm{C}$ followed by $400{ }^{\circ} \mathrm{C}, 900{ }^{\circ} \mathrm{C}$ followed by $440{ }^{\circ} \mathrm{C}, 900{ }^{\circ} \mathrm{C}$ followed by $480{ }^{\circ} \mathrm{C}, 900$

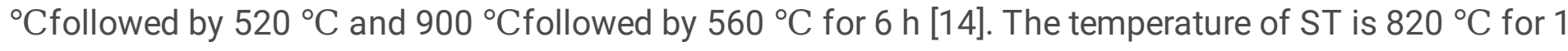
$\mathrm{h}$ and the temperature of AT is $460{ }^{\circ} \mathrm{C}$ for $5 \mathrm{~h}$ [15]. The temperature of the AT is $490{ }^{\circ} \mathrm{C}$ [16]. The temperature of AT is $840^{\circ} \mathrm{C}$ and the temperature of AT is $480^{\circ} \mathrm{C}$ [17]. The temperature of the AT is 510 ${ }^{\circ} \mathrm{C}$ for $1 \mathrm{~h}$ [18]. Figure 15 shows the surface hardness of the test specimens processed by three different $\mathrm{HT}$ methods. The surface hardness of the test specimens can be enhanced due to nanometer-sized $\mathrm{Ni}_{3}$ and $\mathrm{Fe}_{2} \mathrm{Mo}$ intermetallic particles precipitated during the AT. According to the surface hardness of the test specimens, three phenomena were found $\mathbb{X}(\mathrm{a})$ the surface hardness of the test specimens after SAT is the highest, followed by the DAT, (b) the surface hardness of the test specimens is the highest after ST at 760 ${ }^{\circ} \mathrm{C}$ for $1 \mathrm{~h}$, and (c) the optimum HT procedure is ST at $850{ }^{\circ} \mathrm{C}$ for $1 \mathrm{~h}$, followed by AT at $480{ }^{\circ} \mathrm{C}$ for $6 \mathrm{~h}$. The highest surface hardness of the test specimens can be obtained by SAT with the optimum HT procedure. It was seen that the average surface hardness of the test specimens is about HV 545.9 which meets the requirement of the injection mold. 
The process parameters for fabricating high densification injection mold with CCC include hatching space of $60 \mu \mathrm{m}$, layer thickness of $30 \mu \mathrm{m}$, laser power of $50 \mathrm{~W}$, and scanning speed of $200 \mathrm{~mm} / \mathrm{s}$. The general process parameters for fabricating injection mold with CCC include hatching space of $100 \mu \mathrm{m}$, layer thickness of $50 \mu \mathrm{m}$, laser power of $40 \mathrm{~W}$, and scanning speed of $240 \mathrm{~mm} / \mathrm{s}$. It takes 149 hours to manufacture the injection mold by using the high densification process parameters. However, it only takes 49 hours to manufacture the injection mold by the using general parameters. This means that the injection mold manufacture time about $67 \%$ can be saved using the general process parameters. To evaluate the performance of the optimum HT process procedures, a preliminary experiment was conducted. Figure 16 shows the coolant leakage test results before and after HT of the test injection mold with CC. The results revealed that the coolant leakage for test injection mold after HT during the test was not found. However, the test injection mold before HT has coolant leakage of about $38 \mathrm{~g}, 76.5 \mathrm{~g}$, and 115 $\mathrm{g}$ during the test of 1,2 , and $3 \mathrm{~h}$. This means that the proposed method enables quick fabrication of an injection mold with CC by optimum HT process procedures resulting in no coolant leakage in the injection molding process. In this study, the internal surface of the CCC was found are remarkably not smooth. Therefore, improving the internal surface of the $\mathrm{CCC}$ is also an important research issue. The potential polishing methods [19], including abrasive blasting [20], abrasive flow machining [21], electrochemical polishing [22], chemical polishing [23], laser polishing [24], or ultrasonic cavitation abrasive finishing [25] could be employed to improve the internal surface of the CCC .

To verify the effectiveness of the optimum HT process procedures, two sets of injection molds shown in the Figure 17 were fabricated using general process parameters. After optimum HT process procedures, post-process finishing operations of the mold injection inserts was performed for obtaining the desired dimensions of the injection mold using a computer numerical control (CNC) milling machine [26]. In addition, positioning pin holes were maching using a CNC drilling machine. The theoretical relative density was increased from 70.02 to $85.03 \%$. In this study, the MSS powder was used to fabricate injection mold. Some alternative powders, such as 17-4 PH stainless steel, Al-Si alloy, Ni-Ti alloy , 304 stainless steel , 316-L stainless steel, CoCrMo [27], IN 718 alloy, $\mathrm{Ti}^{6} \mathrm{Al}_{4} \mathrm{~V}$ [28], W-Ni-Cu [29], TC 4 [30], Ni [31], Al-Fe-V-Si [32], A357 [33], Cu-15Ni-8S [34], or Inconel 625 [35] could also be used to make functional components for industrial applications. Thus, molds, dies, automotive, aircraft, aerospace, or gear with high mechanical properties can be manufactured by MAM technology with above powders.

To investigate the cooling time of the wax patterns after injection molding, a series of experiments were performed using low-pressure wax injection molding. The wax injection process parameters involve injection time of $2 \mathrm{~s}$ and injection pressure of $0.06 \mathrm{MPa}$. Figure 18 shows the part temperature as a function of the cooling time of the wax pattern after injection molding. The coolant temperature and the coolant flow rate are $25^{\circ} \mathrm{C}$ and $3 \mathrm{~L} / \mathrm{min}$, respectively. Especially, the molded part will cause short shot since the temperature of the injection mold was influenced by the leakage coolant. The cooling times of the wax patterns fabricated by the injection mold with and without coolant leakage are $23 \mathrm{~s}$ and $38 \mathrm{~s}$, respectively. The cooling stage is a sophisticated heat transfer process in the injection molding process. Generally, there are four distinct stages, i.e. filling, packing, cooling, and demolding in the injection 
molding process. To study heat transfer process during the cooling stage, the cycle-averaged temperature distribution represented by the steady-state Laplace heat conduction equation was widely employed to simplify the analysis of the cooling process. Figure 19 shows the schematic illustration of the heat fluxes during the cooling stage after low-pressure wax injection molding. Generally, the heat conduction is usually governed by the partial differential equation. The heat transfer rate must be in equilibrium when the heat balance was established. The heat transfer rate from the molding materials to the mold materials, heat transfer rate from the mold materials to the coolant, and heat transfer rate from the mold materials to the ambient air are symbolized by, and , respectively. Therefore, the heat balance can be expressed by the equation of.The heat from the molten wax material in the mold cavity is taken away by both coolant and exterior surfaces of the mold. The heat balance equation can be simplified by neglecting the heat lost to the surrounded environment since is less than $5 \%$ of the . In addition, the mold materials boundary is assumed to be adiabatic. Therefore, the heat of the molten wax material in the mold cavity is taken away by the coolant moving through the conformal cooling channels after the injection molding. Based on the solidification of the wax patterns, the required cooling time $\left(t_{c}\right)$ of the wax patterns can also be calculated by the following equation [36-38]:

$$
\begin{aligned}
& Q_{m}+Q_{c}+Q_{e}=0 \\
& t_{c}=\frac{s^{2}}{\pi^{2} \alpha} \ln \left[\frac{4}{\pi}\left(\frac{T_{m}-T_{w}}{T_{e}-T_{w}}\right)\right]
\end{aligned}
$$

where $s$ is the thickness of the wax patterns, $T_{m}$ is the melt temperature of the molding material, $T_{e}$ is the average demolding temperature of the wax patterns, is the thermal diffusivity, and $T_{W}$ is the mold cavity surface temperature.

Figure 20 shows the part temperature as a function of the cooling time of the wax pattern for five different coolant temperatures. Two phenomena were found. On is that the cooling times of the wax patterns fabricated by the injection mold without coolant leakage are about $21 \mathrm{~s}, 33 \mathrm{~s}, 45 \mathrm{~s}$, and $112 \mathrm{~s}$ when the coolant temperatures are $21^{\circ} \mathrm{C}, 23^{\circ} \mathrm{C}, 25^{\circ} \mathrm{C}, 27^{\circ} \mathrm{C}$ and $29^{\circ} \mathrm{C}$, respectively. The other one is that the cooling time of the wax pattern was obvious longer when the coolant temperature is $29^{\circ} \mathrm{C}$. According to the results described above, determination of the coolant temperature is an important factor affecting the injection molding yield and molding cycle time based on the cooling shrinkage rate and cooling time of the wax pattern.

The coolant flow rate is an important issue on the cooling efficiency for injection mold with conformal cooling channels. In general, the turbulent flow (Reynolds number $>4,000$ ) provides three to five times as much heat transfer as laminar flow (Reynolds number $<2,100$ ). The coolant flow performs the turbulence when the Reynolds number exceeds the 4,000. In this study, four different coolant flow rates were used in this study, i.e. $2.5 \mathrm{~L} / \mathrm{min}, 3 \mathrm{~L} / \mathrm{min}, 3.5 \mathrm{~L} / \mathrm{min}$, and $4 \mathrm{~L} / \mathrm{min}$. The Reynolds number for four different coolant 
flow rates is about $4927,5913,6897$, and 7883 , respectively. To understand the effects of coolant flow rates on the cooling time of the wax pattern, a series tests was carried out. Figure 21 shows the part temperature as a function of the cooling time for four different coolant flow rates. In particular, the cooling time of the wax pattern is approximately $38 \mathrm{~s}$. This means that the cooling time of the wax pattern was found not affected by the different coolant flow rates while the coolant reaches the turbulent flow. However, the layout of CCC was not optimized. Therefore, optimization of CCC using the design of experiment method is also an important research issue. In particular, the a discrepancy in the cooling times of the wax patterns between the experimental and numerical simulation results was attributed to the inconsistency in initial and boundary conditions. Thus, reducing the discrepancy in the cooling times of the wax patterns between the experimental and numerical simulation results is also an important research issue. The CCC embedded in the injection mold is series circuits. Mixing series circuits [39] to keep turbulent flow and parallel circuits [40] to improve temperature homogeneity is also an important research issue.

In general, a high-temperature HT was widely employed to join small particles for reducing the pore size to obtain sufficient mechanical or thermal properties since precipitation in solids can produce many different sizes of particles during optimum HT process procedures. Figure 22 shows the microstructural developments after optimal HT. It was shown that the irregular pores or void defects were reduced gradually through the recrystallization $\mathrm{HT}$, resulting in significant reduction in the porosity of the injection mold. In addition, the textural anisotropy and internal residual stresses of the direct metal printed injection mold built with DMLS can also be improved significantly through the recrystallization HT. This result reveals that the mechanical properties and microstructure were improved after optimum HT process procedures. Based on the results described above, the remarkable findings of this study can be used for the fabrication of molds or dies efficiently and economically for trial production in the mold or die industries. The wax pattern can be fabricated by wax injection molding via MSS injection mold processed by optimum HT procedures, which can be employed for investment casting (IC).

According to the foregoing results, the findings of this study are very practical and provide the greatest application potential in the IC industry. The main contributions in this study is to propose a low-cost and highly efficient method of reducing coolant leakage during wax injection molding 3D printed conformally cooled injection molds. However, some distinct mold defects, including melt, ball formation, swelling, cracking, residual stress, or delamination were not addressed. In addition, some alternative MAM technologies, such as directed energy deposition, electron beam melting, diffusion bonding, selective laser sintering, or selective laser melting can also be used to make injection molds. The molds or died fabricated by the MAM technologies could also be employed for micro-injection molding, thermoforming, forging, hot embossing, blow molding, metal injection molding, die casting, hot extrusion, injectioncompression molding, rotational molding, thermoforming, transfer molding, or hot stamping. The microstructure of the injection mold manufactured by DMLS can be manipulated by laser power [41], hatch space [42], scanning speed, scanning strategy [43], or powder layer thickness. Normally, slower scanning speed, or higher laser power will contribute to grain size growth. These issues are currently being investigated and the results will be presented in a later study. 


\section{Conclusions}

MAM has been widely used in high-value applications, such as aerospace or automotive industries. MSS powder was used in DMLS process to fabricate the injection mold with sophisticated CCC. However, manufacturing a high densification injection mold or die is a time-consuming process as well as low yield. This method provides a more efficient means of reducing coolant leakage for direct metal printed injection mold incorporated CCCs by integration of mold making using general process parameters and optimum HT process procedures. The cooling time of the wax pattern in the low-pressure wax injection molding was numerically and experimentally examined. The main contributions and findings from this study are summarized as follows:

1. The remarkable findings in this study are very practical and provide the greatest application potential for the fabrication of molds or die efficiently and economically in the mold or die industry.

2. A low-cost and highly efficient method of reducing coolant leakage for direct metal printed injection mold with CC has been proposed.

3. A recrystallization mechanism of reducing coolant leakage for direct metal printed injection mold with CC has been demonstrated.

4. The optimum HT procedure is ST at $850^{\circ} \mathrm{C}$ for $1 \mathrm{~h}$, followed by AT at $480^{\circ} \mathrm{C}$ for $6 \mathrm{~h}$. The highest surface hardness about HV 545.9 can be obtained via the optimum HT procedure.

5. This new method employs general printing procedures to fabricate the green injection mold rapidly and then uses optimum heat treatment process procedures to improve microstructures of the green injection mold.

\section{Declarations}

Conflicts of interest/Competing interests (Not applicable)

Funding

This study received financial support by the Ministry of Science and Technology of Taiwan under contract nos. MOST 109-2637-E-131-004 and MOST 107-2221-E-131-018.

Availability of data and material (Data and materials are available)

Code availability (Not applicable)

Authors' contributions

Arthur $1 \otimes W r o t e$ the paper/ Conceived and designed the analysis/ Performed the analysis/Conceptualization

Arthur 2/3®Collected the data/Contributed data or analysis tools 
Ethics approval (Not applicable)

Consent to participate (We are agreeing to participate)

Consent for publication (We are agreeing to publish this work)

\section{References}

1. Kanbur, B.B., Suping, S. \& Duan, F. Design and optimization of conformal cooling channels for injection molding: a review. Int J Adv Manuf Technol 106, 3253-3271 (2020).

2. Mukhtarkhanov, M.; Perveen, A.; Talamona, D. Application of Stereolithography Based 3D Printing Technology in Investment Casting. Micromachines2020, 11, 946. https://doi.org/10.3390/mi11100946

3. Kotz, F.; Mader, M.; Dellen, N.; Risch, P.; Kick, A.; Helmer, D.; Rapp, B.E. Fused Deposition Modeling of Microfluidic Chips in Polymethylmethacrylate. Micromachines2020, 11, 873. https://doi.org/10.3390/mi11090873

4. Rehmani, M.A.A.; Jaywant, S.A.; Arif, K.M. Study of Microchannels Fabricated Using Desktop Fused Deposition Modeling Systems. Micromachines 2021, 12, 14. https://doi.org/10.3390/mi12010014

5. Attarzadeh, F., Fotovvati, B., Fitzmire, M. et al. Surface roughness and densification correlation for direct metal laser sintering. Int J Adv Manuf Technol 107, 2833-2842 (2020).

6. Contaldi, V., Del Re, F., Palumbo, B. et al. Mechanical characterisation of stainless steel parts produced by direct metal laser sintering with virgin and reused powder. Int J Adv Manuf Technol 105, 3337-3351 (2019).

7. Kundu, S., Hussain, M., Kumar, V. et al. Direct metal laser sintering of TiN reinforced Ti6Al4V alloy based metal matrix composite: Fabrication and characterization. Int J Adv Manuf Technol 97, 26352646 (2018).

8. AlMangour, B., Yang, J. Understanding the deformation behavior of 17-4 precipitate hardenable stainless steel produced by direct metal laser sintering using micropillar compression and TEM. Int $J$ Adv Manuf Technol 90, 119-126 (2017).

9. Alafaghani, A., Qattawi, A. \& Castañón, M.A.G. Effect of manufacturing procedures on the microstructure and mechanical properties of metal laser sintering parts of precipitate hardenable metals. Int J Adv Manuf Technol 99, 2491-2507 (2018).

10. Mazzarisi, M., Campanelli, S.L., Angelastro, A. et al. Phenomenological modelling of direct laser metal deposition for single tracks. Int J Adv Manuf Technol 111, 1955-1970 (2020).

11. Mizoshiri, M.; Nishitani, K.; Hata, S. Effect of Heat Accumulation on Femtosecond Laser Reductive Sintering of Mixed CuO/NiO Nanoparticles. Micromachines 2018, 9, 264. https://doi.org/10.3390/mi9060264

12. Matamoros, M.; Gómez-Blanco, J.C.; Sánchez, Á.J.; Mancha, E.; Marcos, A.C.; Carrasco-Amador, J.P.; Pagador, J.B. Temperature and Humidity PID Controller for a Bioprinter Atmospheric Enclosure 
System. Micromachines 2020, 11, 999. https://doi.org/10.3390/mi11110999

13. Mc Gee, K.; Anandarajah, P.; Collins, D. Current Progress towards the Integration of Thermocouple and Chipless RFID Technologies and the Sensing of a Dynamic Stimulus. Micromachines 2020, 11, 1019. https://doi.org/10.3390/mi11111019

14. Bai, D. Wang, Y. Q. Yang, \& H. Wang, " Effect of heat treatment on the microstructure and mechanical properties of maraging steel by selective laser melting," Materials Science \& Engineering A, Volume 760, Pages 105-117, 2019.

15. Mutua, S. Nakata, T. Onda, \& Z. C. Chen, " Optimization of selective laser melting parameters and influence of post heat treatment on microstructure and mechanical properties of maraging steel," Materials \& Design, 139, Pages 486-497, 2018.

16. Song, Q.Tang, Q.Feng, S.Ma, R.Setchi, Y.Liu, Q.Hanb, X.Fan, M.Zhang, " Effect of heat treatment on microstructure and mechanical behaviours of $18 \mathrm{Ni}-300$ maraging steel manufactured by selective laser melting, " Optics \& Laser Technology, Volume 120, December 2019, 105725.

17. Bai, Y. Yang, D Wang, M Zhang " Influence mechanism of parameters process and mechanical properties evolution mechanism of maraging steel 300 by selective laser melting," Materials Science \& Engineering A, Volume 703, Pages 116-123, 2017.

18. Bodziak, K.S. Al-Rubiae, L.D Valentina, F.H Lafratta, E.C Santos, A .M Zanatta, Y.Chen, " Precipitation in 300 grade maraging steel built by selective laser melting: Aging at $510^{\circ} \mathrm{C}$ for $2 \mathrm{~h}$," Materials Characterization, Volume 151, Pages 73-83, May 2019.

19. Lin, B.; Jiang, X.-M.; Cao, Z.-C.; Li, Y. Novel Disc Hydrodynamic Polishing Process and Tool for HighEfficiency Polishing of Ultra-Smooth Surfaces. Micromachines2018, 9, 333. https://doi.org/10.3390/mi9070333

20. Jin, S.Y., Pramanik, A., Basak, A.K. et al. Burr formation and its treatments-a review. Int J Adv Manuf Technol (2020). https://doi.org/10.1007/s00170-020-05203-2

21. Munhoz, M.R., Dias, L.G., Breganon, R. et al. Analysis of the surface roughness obtained by the abrasive flow machining process using an abrasive paste with oiticica oil. Int $\mathrm{J}$ Adv Manuf Technol 106, 5061-5070 (2020).

22. Dong, G., Marleau-Finley, J. \& Zhao, Y.F. Investigation of electrochemical post-processing procedure for Ti-6Al-4V lattice structure manufactured by direct metal laser sintering (DMLS). Int J Adv Manuf Technol 104, 3401-3417 (2019).

23. Tyagi, P., Goulet, T., Riso, C. et al. Reducing surface roughness by chemical polishing of additively manufactured 3D printed 316 stainless steel components. Int J Adv Manuf Technol 100, 2895-2900 (2019).

24. Yung, K.C., Zhang, S.S., Duan, L. et al. Laser polishing of additive manufactured tool steel components using pulsed or continuous-wave lasers. Int J Adv Manuf Technol 105, 425-440 (2019).

25. Nagalingam, A.P., Yeo, S.H. Effects of ambient pressure and fluid temperature in ultrasonic cavitation machining. Int J Adv Manuf Technol 98, 2883-2894 (2018). 
26. Lee, W.-L.; Shih, P.-J.; Hsu, C.-C.; Dai, C.-L. Fabrication and Characterization of Flexible Thermoelectric Generators Using Micromachining and Electroplating Techniques. Micromachines2019, 10, 660. https://doi.org/10.3390/mi10100660

27. Song, C., Yang, Y., Wang, Y. et al. Research on rapid manufacturing of CoCrMo alloy femoral component based on selective laser melting. Int J Adv Manuf Technol 75, 445-453 (2014).

28. Yamamoto, S., Azuma, H., Suzuki, S., Kajino, S., Sato, N., Okane, T., ... \& Shimizu, T. (2019). Melting and solidification behavior of Ti-6Al-4V powder during selective laser melting. The International Journal of Advanced Manufacturing Technology, 103(9-12), 4433-4442.

29. Zhang, D., Cai, Q., Liu, J. et al. Microstructural evolvement and formation of selective laser melting W-Ni-Cu composite powder. Int J Adv Manuf Technol 67, 2233-2242 (2013).

30. Cao, L.. Study on the numerical simulation of laying powder for the selective laser melting process. The International Journal of Advanced Manufacturing Technology, 105(5-6), 2253-2269 (2019).

31. Li, R., Liu, J., Shi, Y., Wang, L., \& Jiang, W.. Balling behavior of stainless steel and nickel powder during selective laser melting process. The International Journal of Advanced Manufacturing Technology, 59(9-12), 1025-1035 (2012).

32. Sun, S., Zheng, L., Liu, Y., Liu, J., \& Zhang, H.. Selective laser melting of Al-Fe-V-Si heat-resistant aluminum alloy powder: modeling and experiments. The International Journal of Advanced Manufacturing Technology, 80(9-12), 1787-1797 (2015).

33. Tonelli, L., Liverani, E., Valli, G., Fortunato, A., \& Ceschini, L.. Effects of powders and process procedures on density and hardness of A357 aluminum alloy fabricated by selective laser melting. The International Journal of Advanced Manufacturing Technology, 106(1-2), 371-383 (2020).

34. Zhang, G., Chen, C., Wang, X., Wang, P., Zhang, X., Gan, X., \& Zhou, K.. Additive manufacturing of finestructured copper alloy by selective laser melting of pre-alloyed $\mathrm{Cu}-15 \mathrm{Ni}-8 \mathrm{Sn}$ powder. The International Journal of Advanced Manufacturing Technology, 96(9-12), 4223-4230 (2018).

35. Criales, L.E., Arısoy, Y.M. \& Özel, T. Sensitivity analysis of material and process procedures in finite element modeling of selective laser melting of Inconel 625. Int J Adv Manuf Technol 86, 2653-2666 (2016).

36. S. Rao, G. Schumacher, Design Formulas for Plastics Engineers, second ed., Hanser Verlag: Munich, 2004, Pages 145-148.

37. L. White, E. C. Bernhardt, Computer Aided Engineering For Injection Molding, Hanser, New York, 1983, Pages 105-106.

38. Shayfull, S. Sharif, A. M. Zain, R. M. Saad, M. A. Fairuz," Milled groove square shape conformal cooling channels in injection molding process", Mater. Manuf. Process. , Volume 28, 2013, Pages 884-891.

39. Abbès, B., Abbès, F., Abdessalam, H. et al. Finite element cooling simulations of conformal cooling hybrid injection molding tools manufactured by selective laser melting. Int J Adv Manuf Technol 103, 2515-2522 (2019). 
40. Kuo, CC., Jiang, ZF. \& Lee, JH. Effects of cooling time of molded parts on rapid injection molds with different layouts and surface roughness of conformal cooling channels. Int J Adv Manuf Technol 103, 2169-2182 (2019).

41. Abate, K.M., Nazir, A. \& Jeng, JY. Design, optimization, and selective laser melting of vin tiles cellular structure-based hip implant. Int J Adv Manuf Technol 112, 2037-2050 (2021).

42. Marin, F., de Souza, A.F., Ahrens, C.H. et al. A new hybrid process combining machining and selective laser melting to manufacture an advanced concept of conformal cooling channels for plastic injection molds. Int J Adv Manuf Technol (2021).

43. Dilberoglu, U.M., Gharehpapagh, B., Yaman, U. et al. Current trends and research opportunities in hybrid additive manufacturing. Int J Adv Manuf Technol (2021).

\section{Figures}




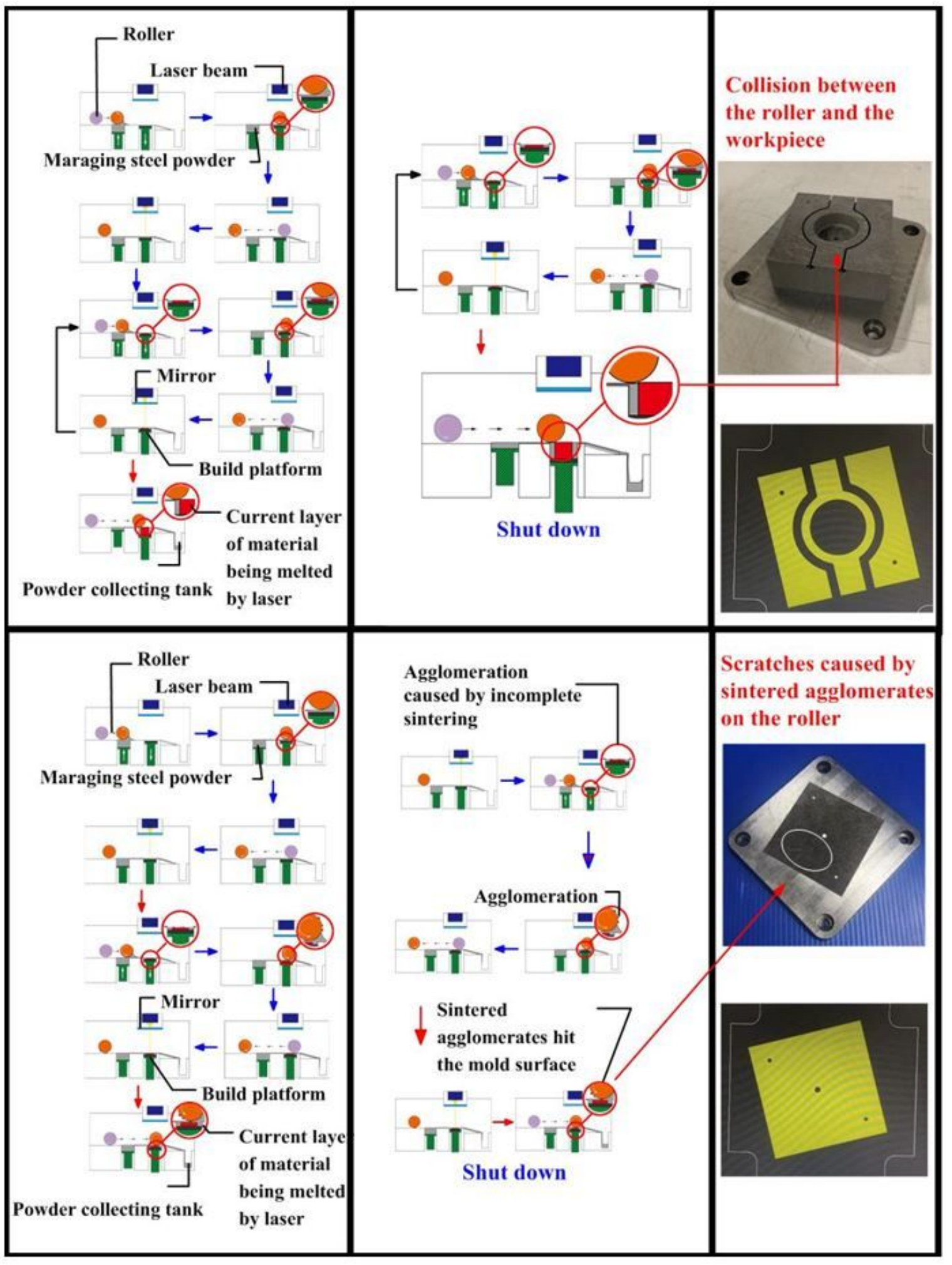

Figure 1

Failed direct metal printed injection molds 


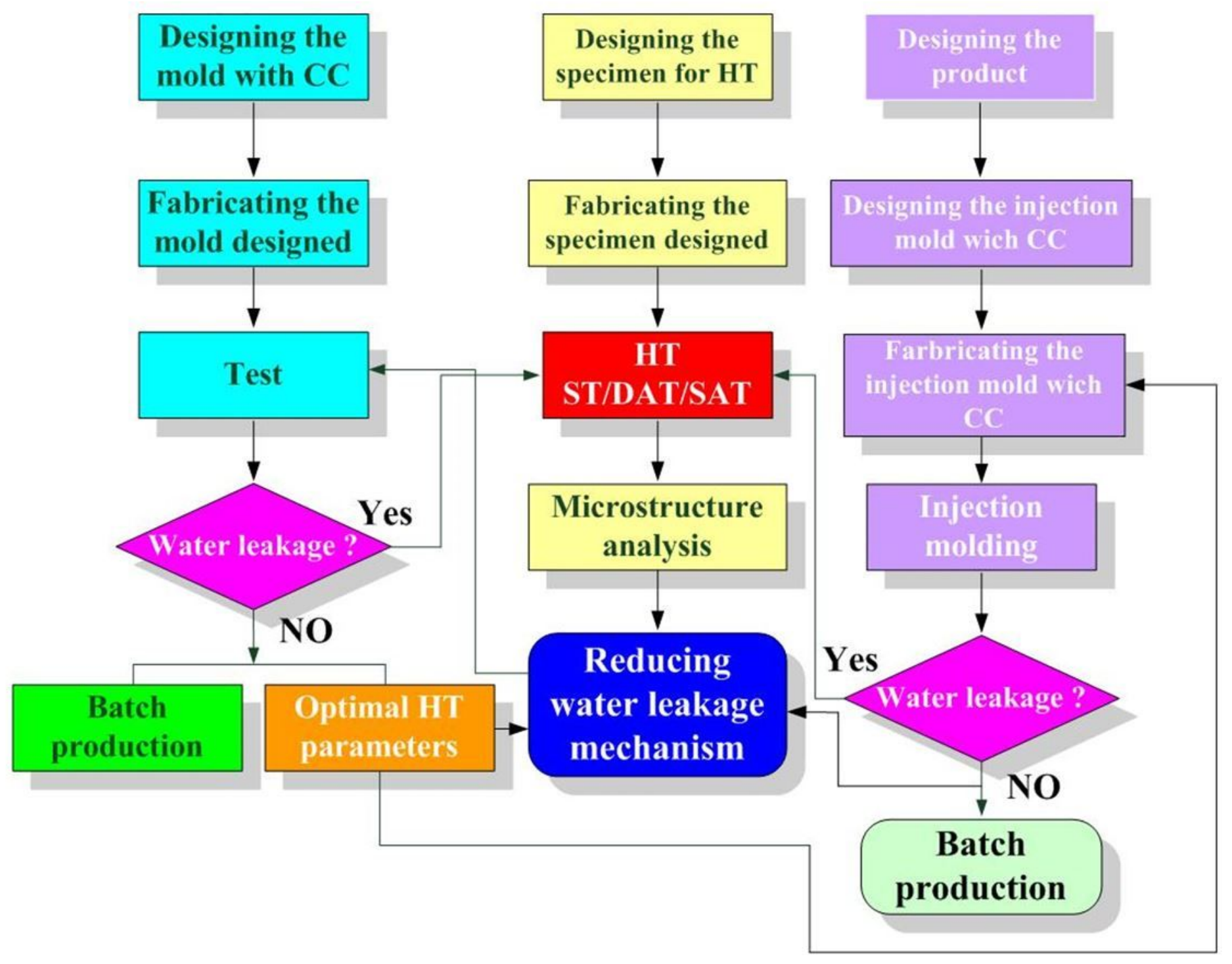

Figure 2

Research process of this study 

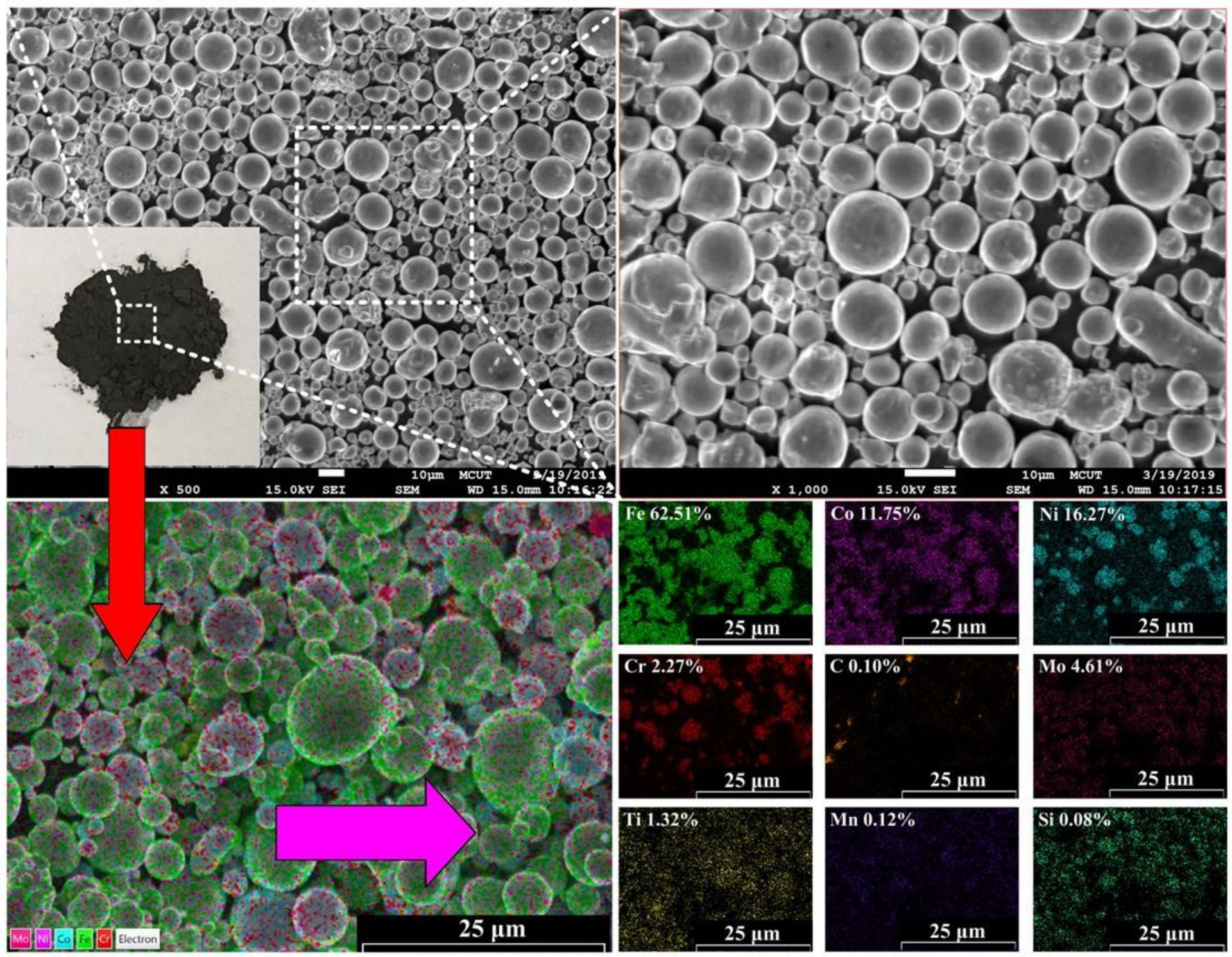

Figure 3

SEM and EDS images of the MSS powder 

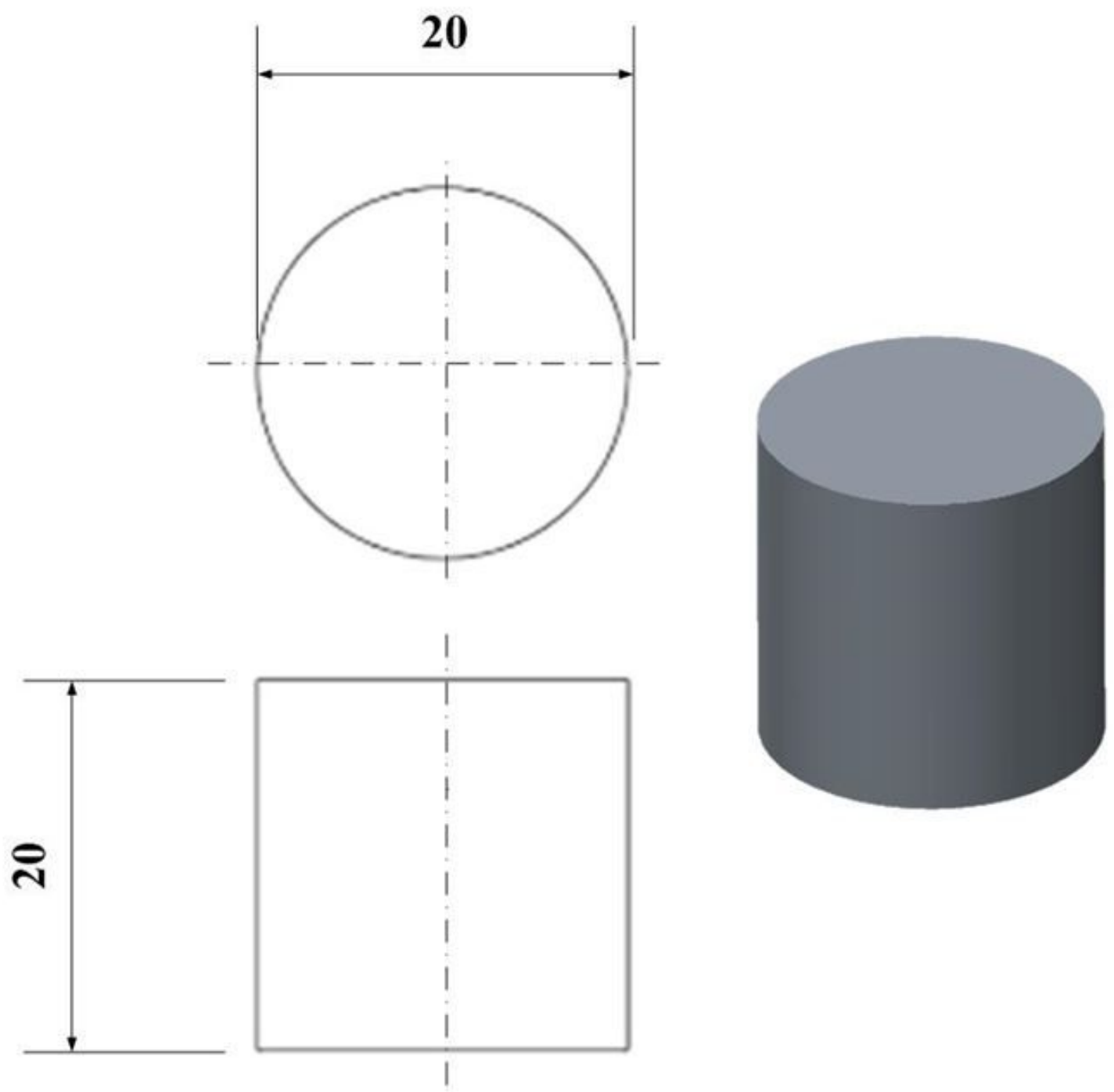

\section{Unit:mm}

Figure 4

CAD model and dimensions of the heat treatment test specimen 

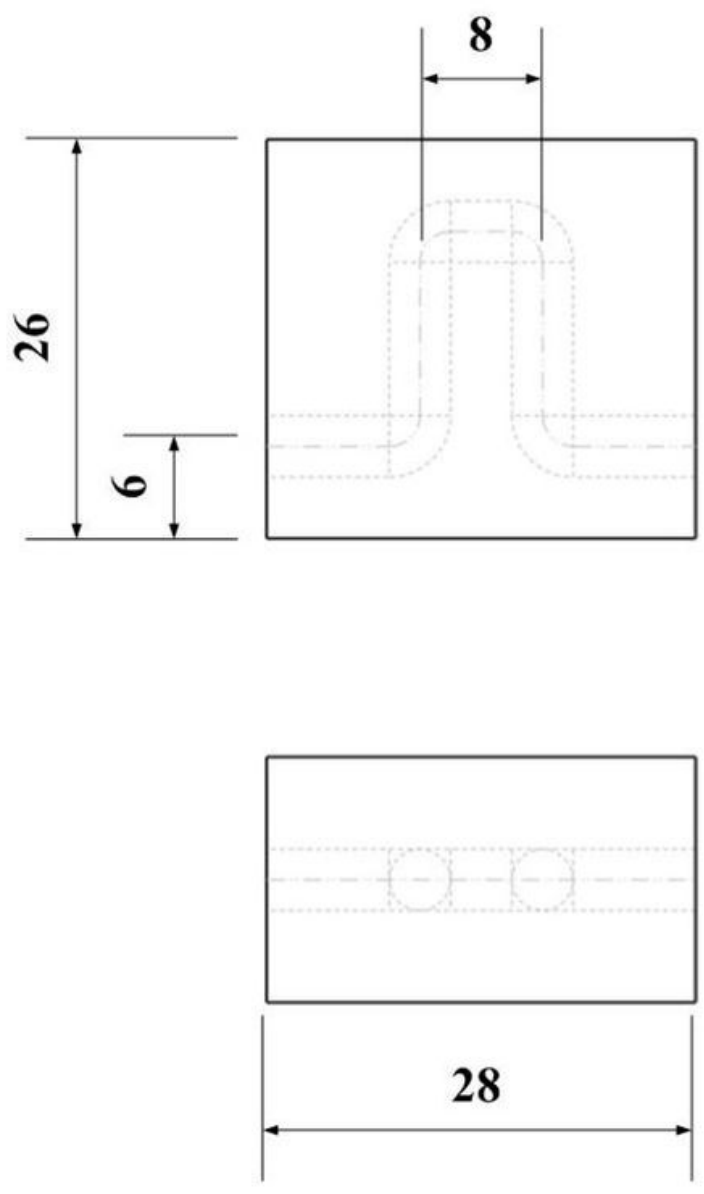

Figure 5

CAD model and dimensions of the test mold with CC
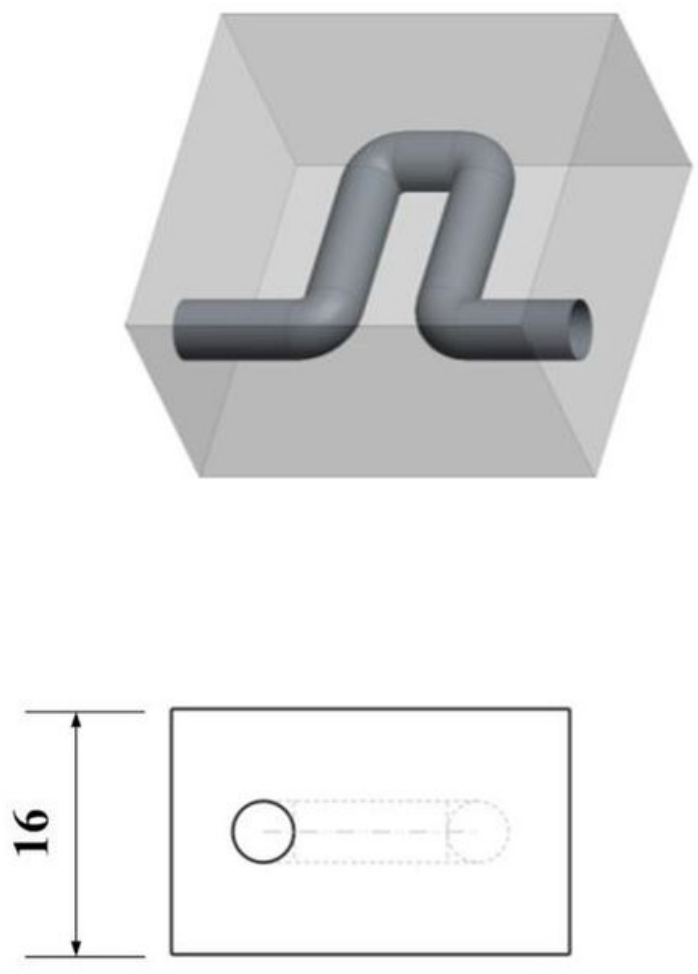

Unit:mm 

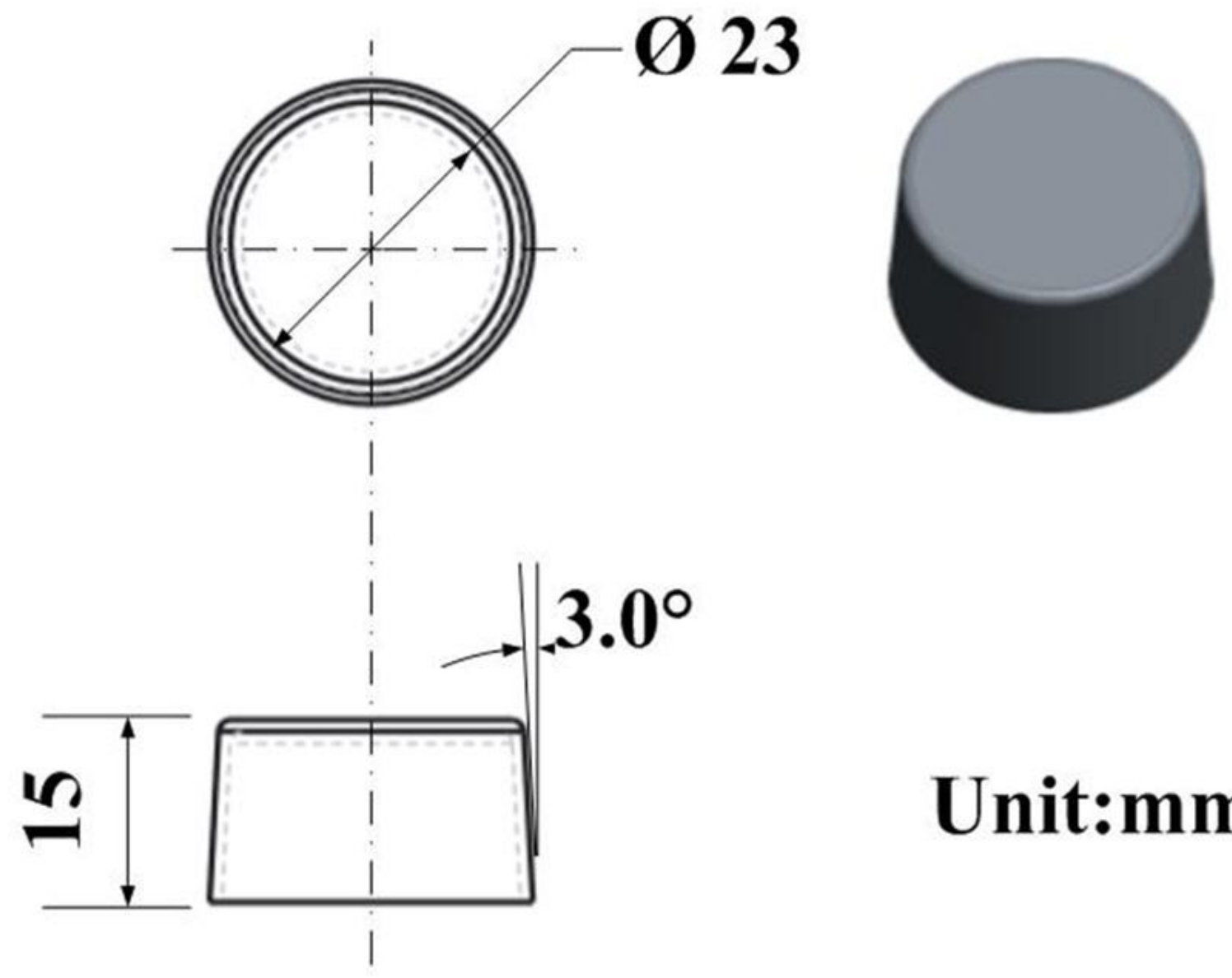

\section{Unit:mm}

Figure 6

CAD model and dimensions of the injection molded product

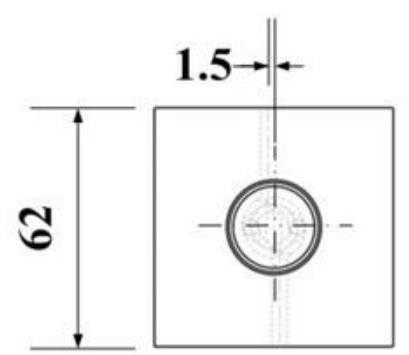

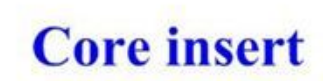
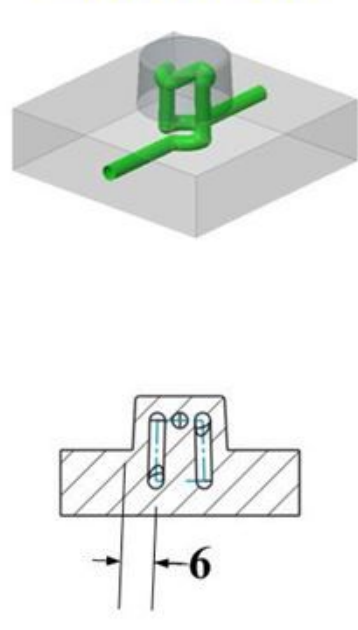

Unit:mm

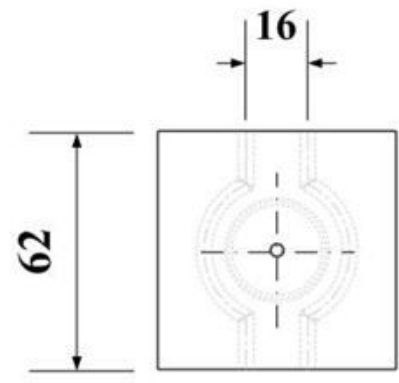

Cavity insert
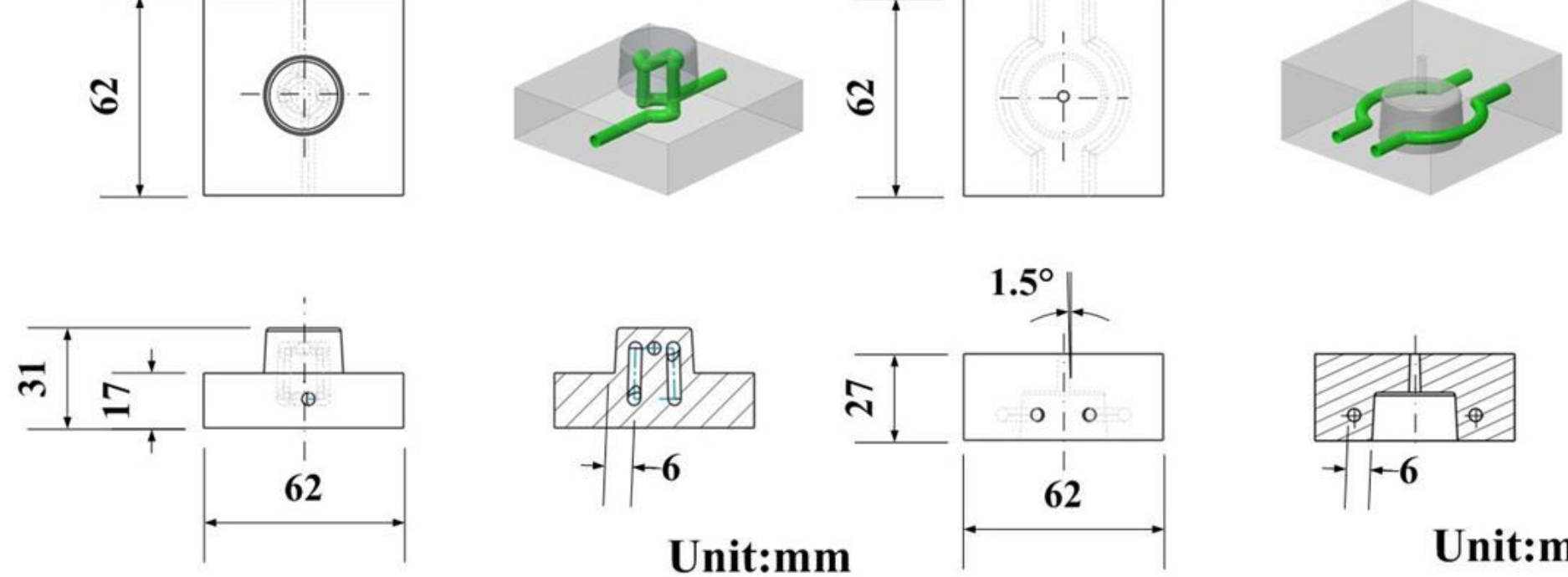

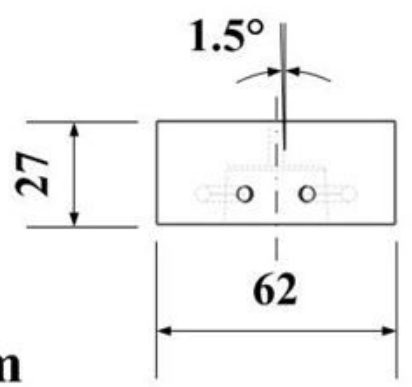

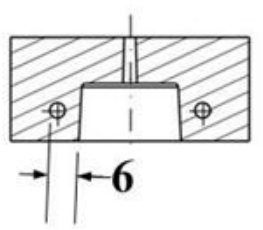

Unit:mm 
Figure 7

CAD model and dimensions of the injection mold with CCC

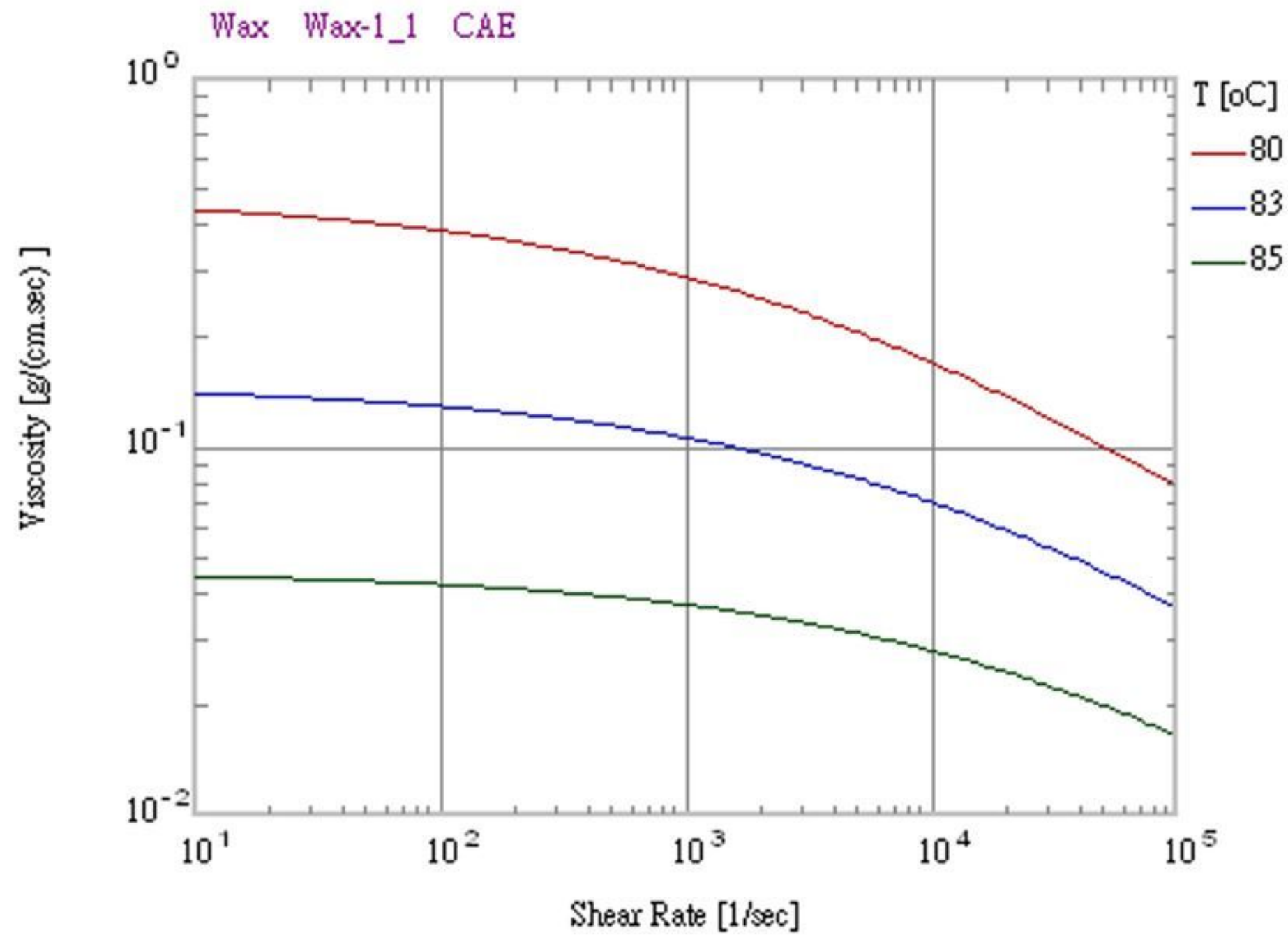

Figure 8

Viscosity of the molding material 


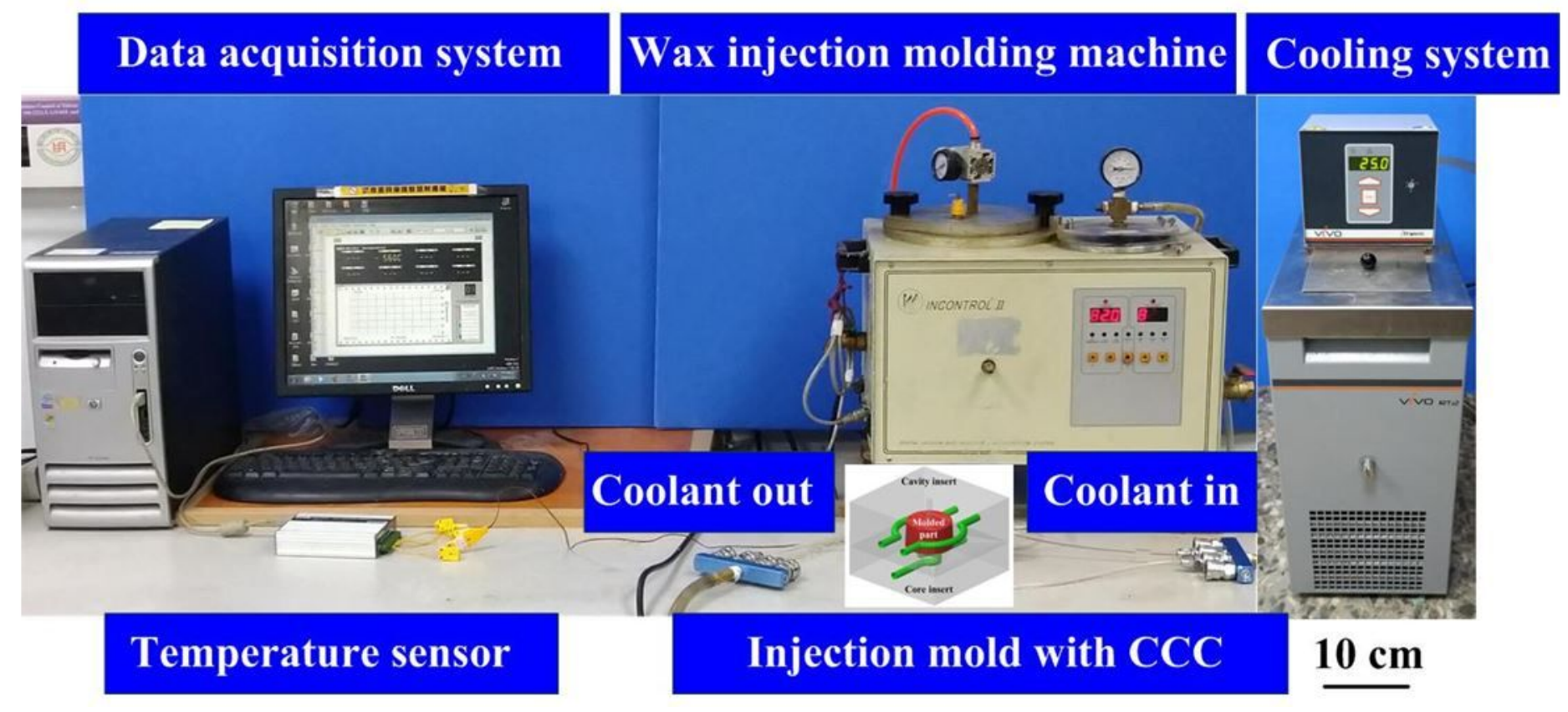

Figure 9

Experimental setup for investigating the cooling performance of the injection mold with and without CCC 

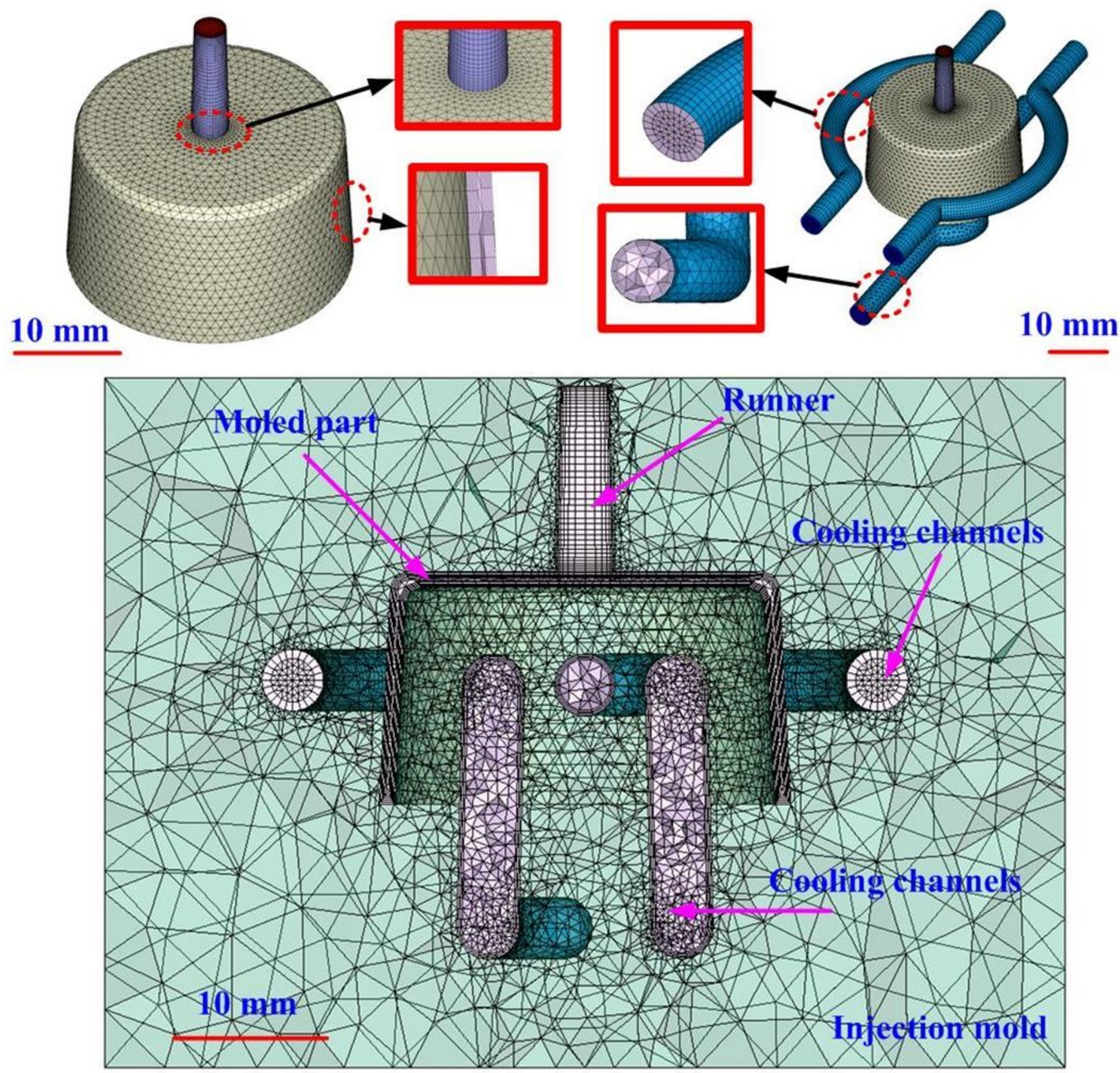

Figure 10

Mesh sections of the injection mold, conformal cooling channels, and injection molded parts 

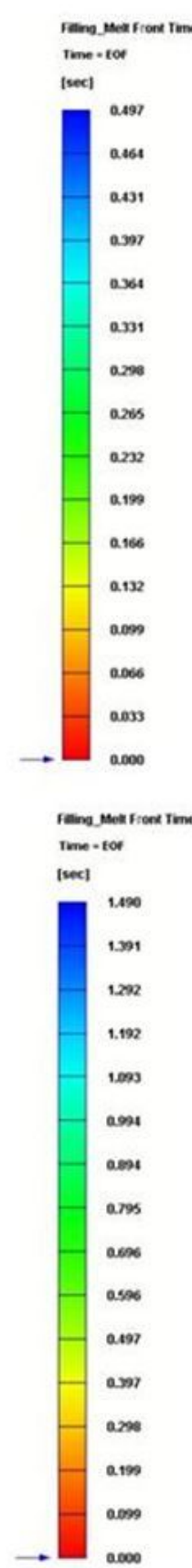
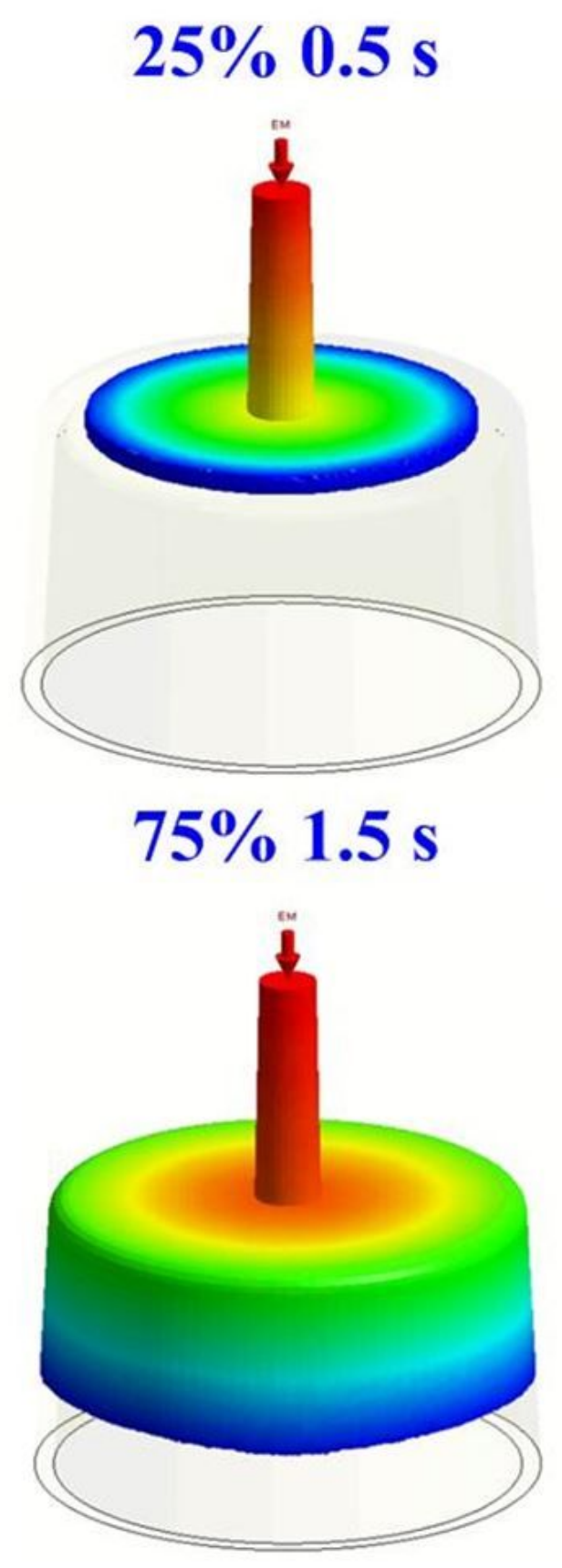
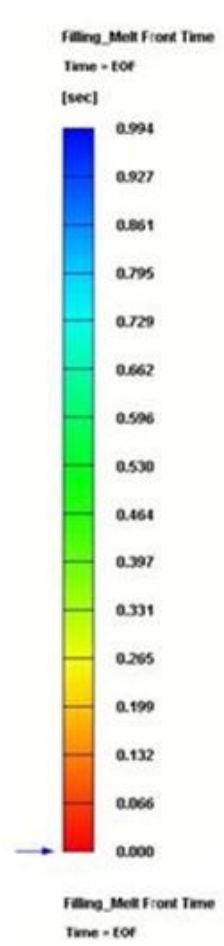

|sec|

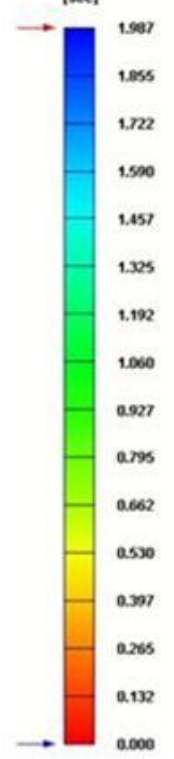

$50 \% 1 \mathrm{~s}$

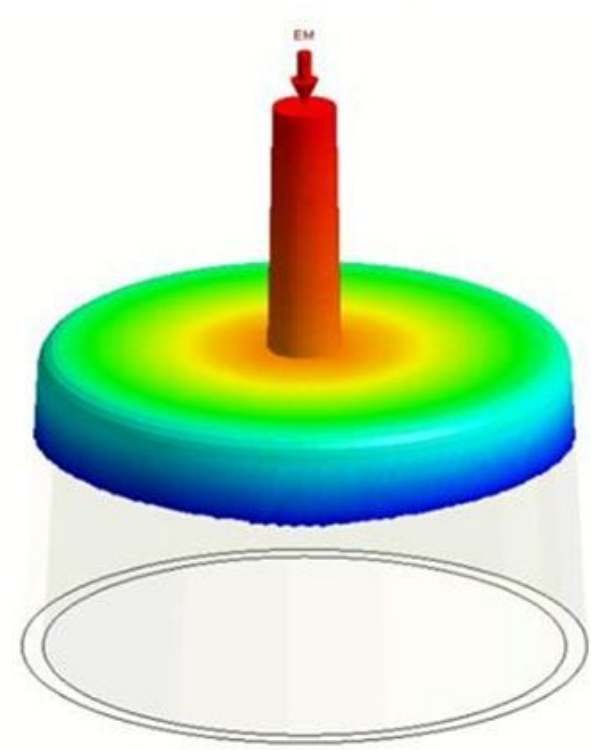

$100 \% 2 \mathrm{~s}$

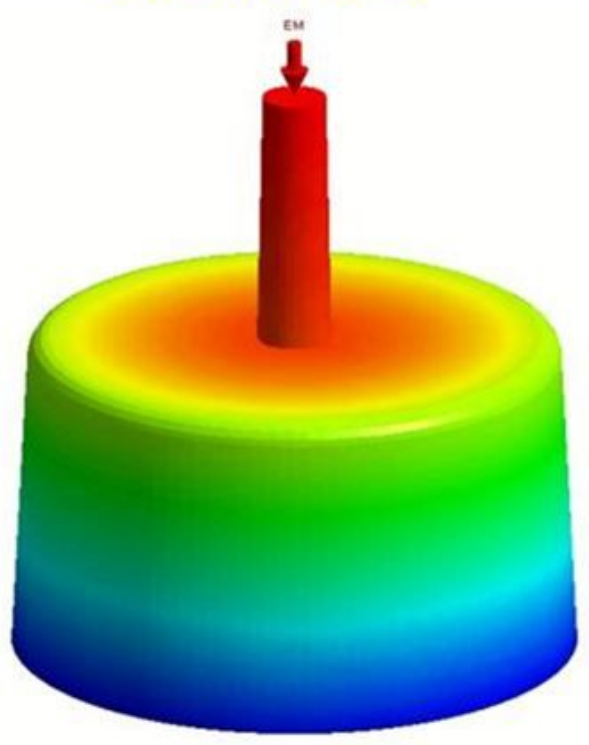

Figure 11

Simulation results of the filling of the molded part at the EOF 

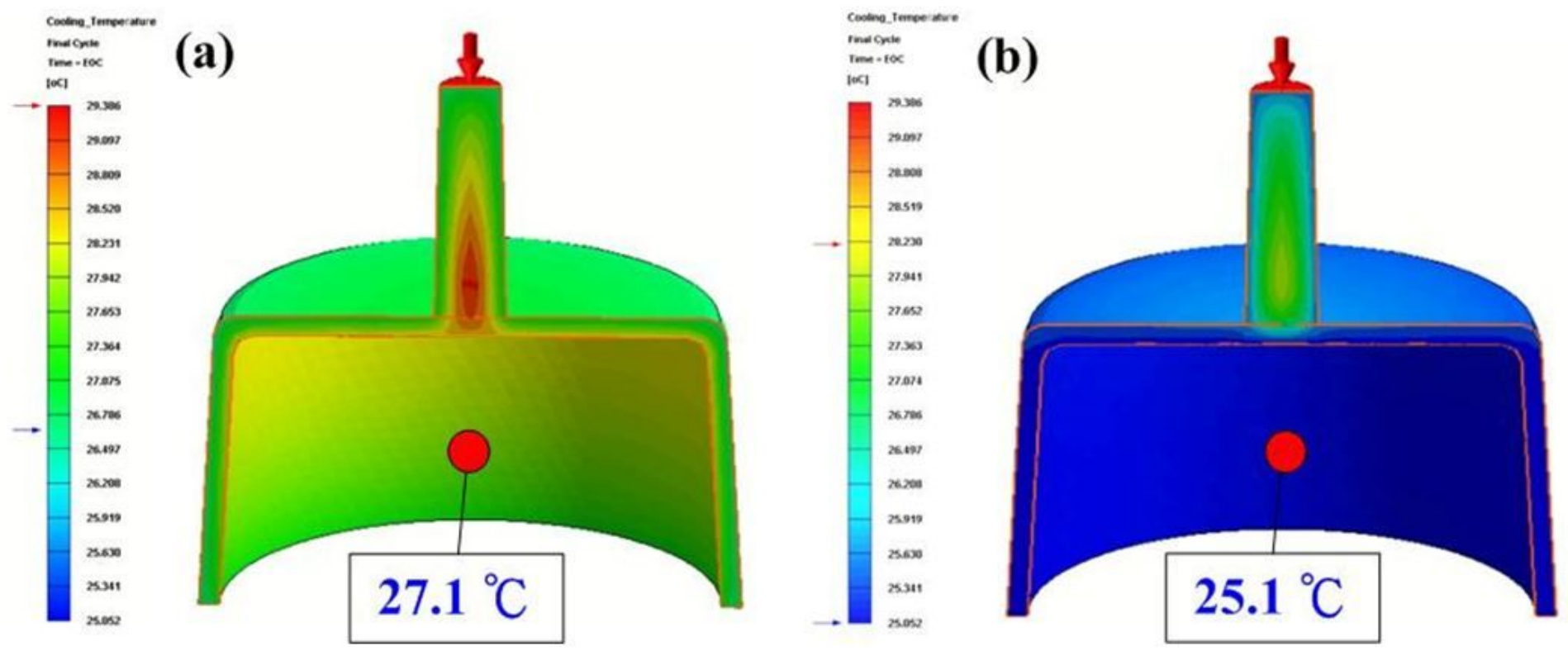

Figure 12

Numerical simulation results of the part temperature difference at the EOC for the injection mold (a) without CCC and (b) with CCC

(a)
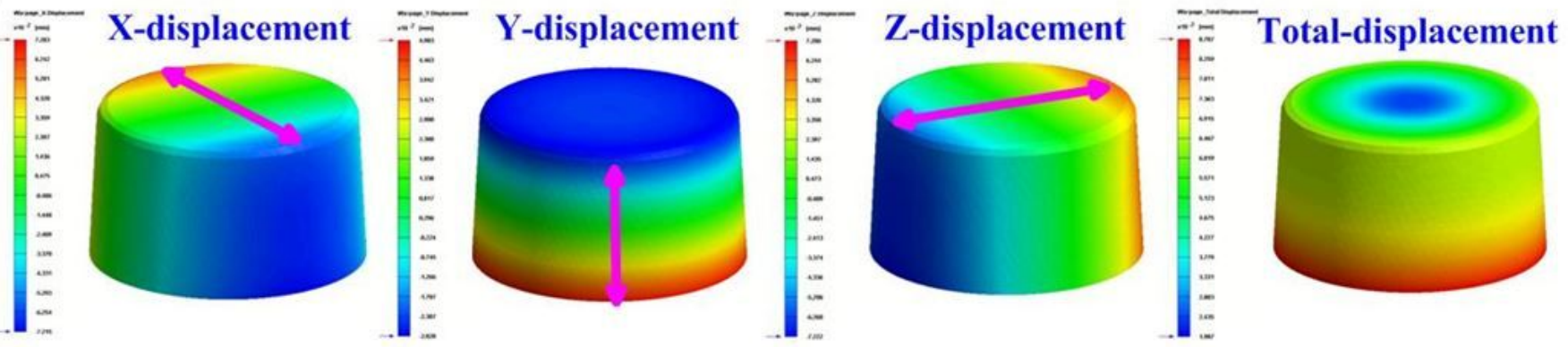

(b)

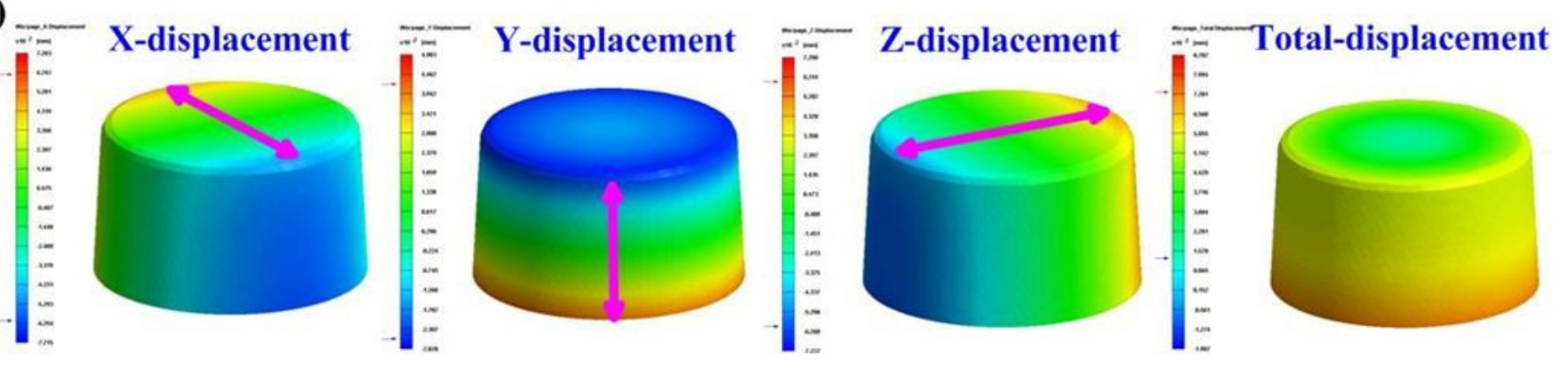

Figure 13

Numerical simulation results of the $x$-displacement, $y$-displacement, z-displacement, and totaldisplacement of the molded part for the injection mold (a) without CCC and (b) with CCC 


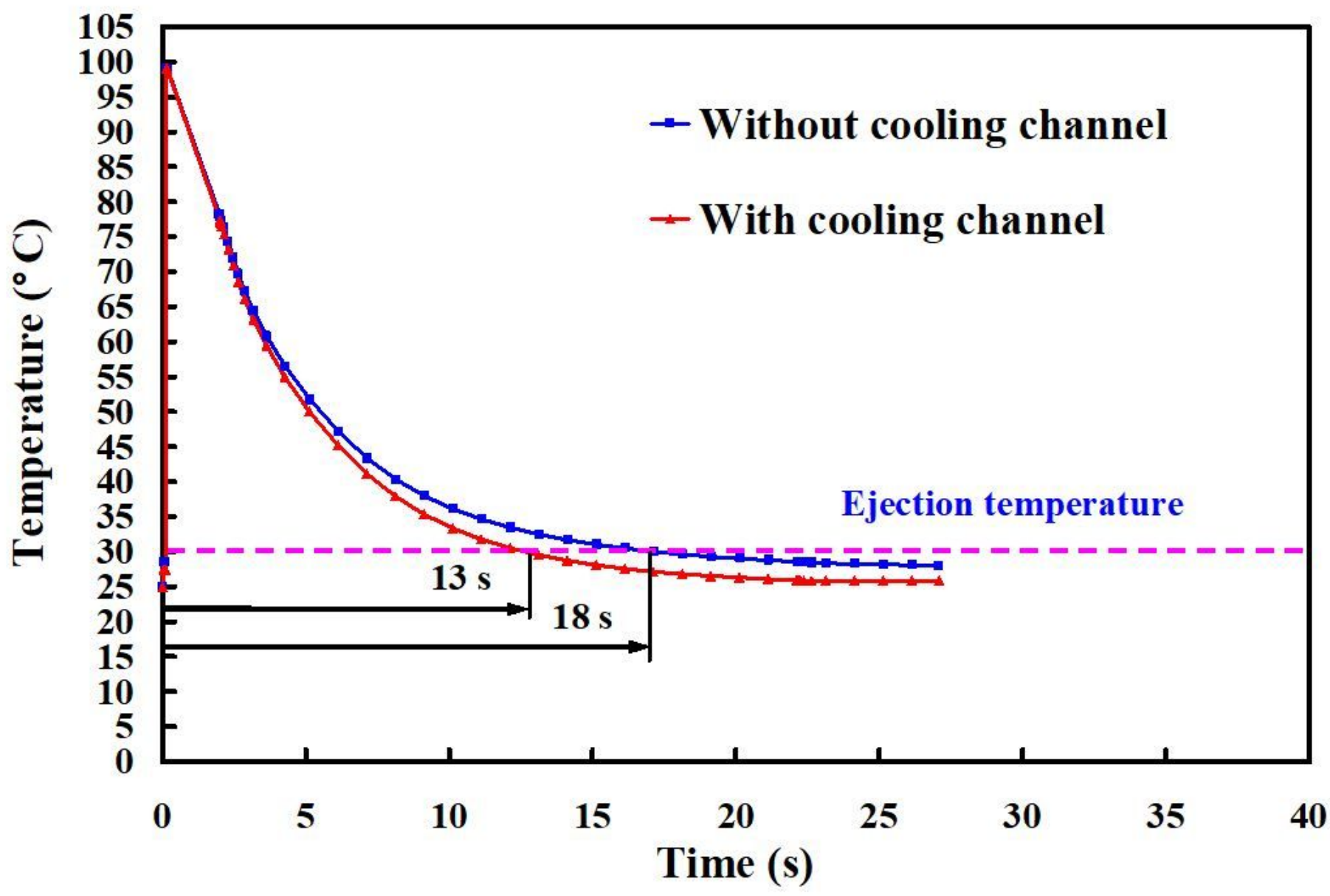

Figure 14

Numerical simulation results of the cooling time of the molded part for the injection mold with and without CCC at the EOP 


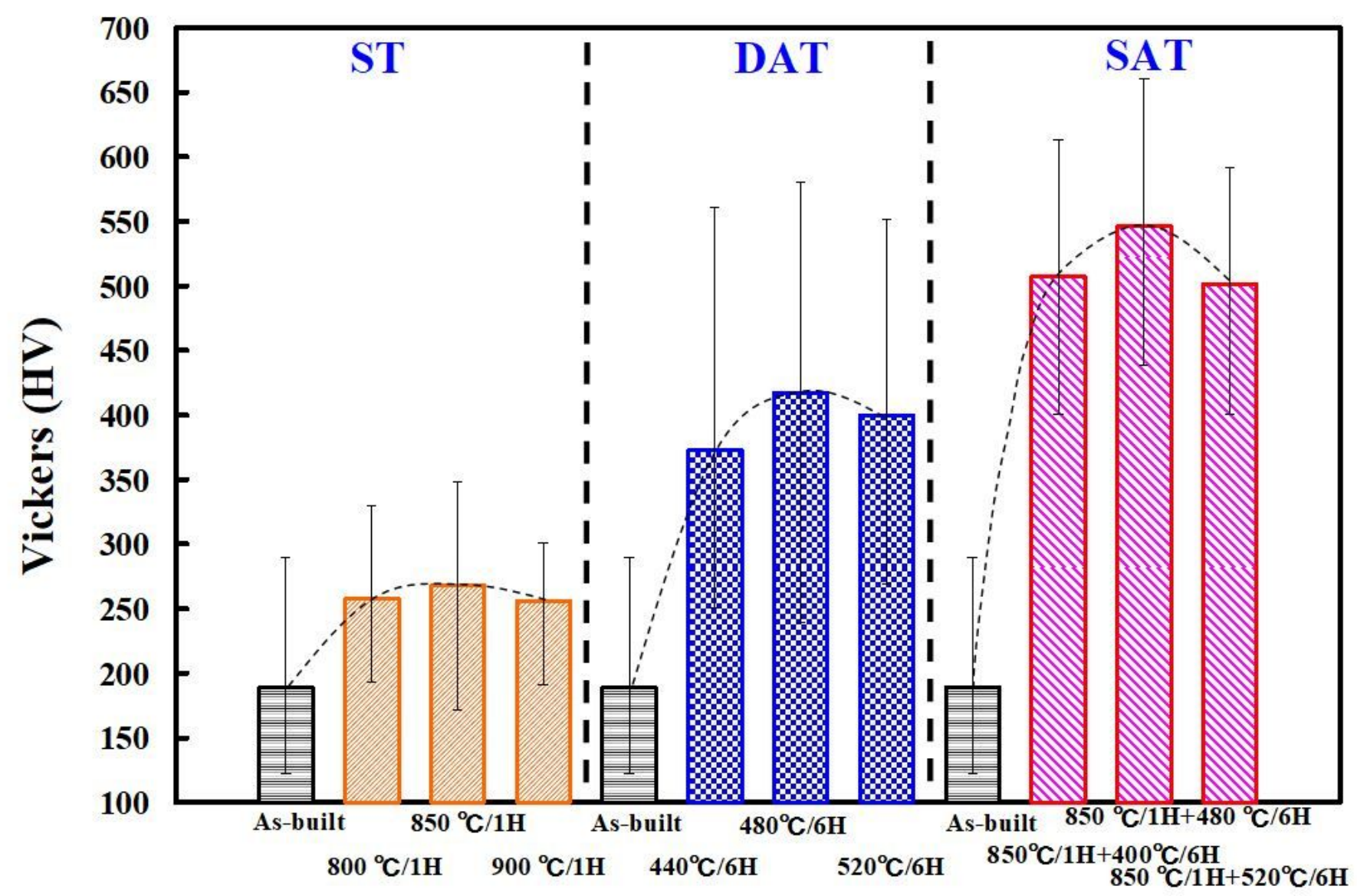

Figure 15

Surface hardness of the test specimens processed by three different HT methods 


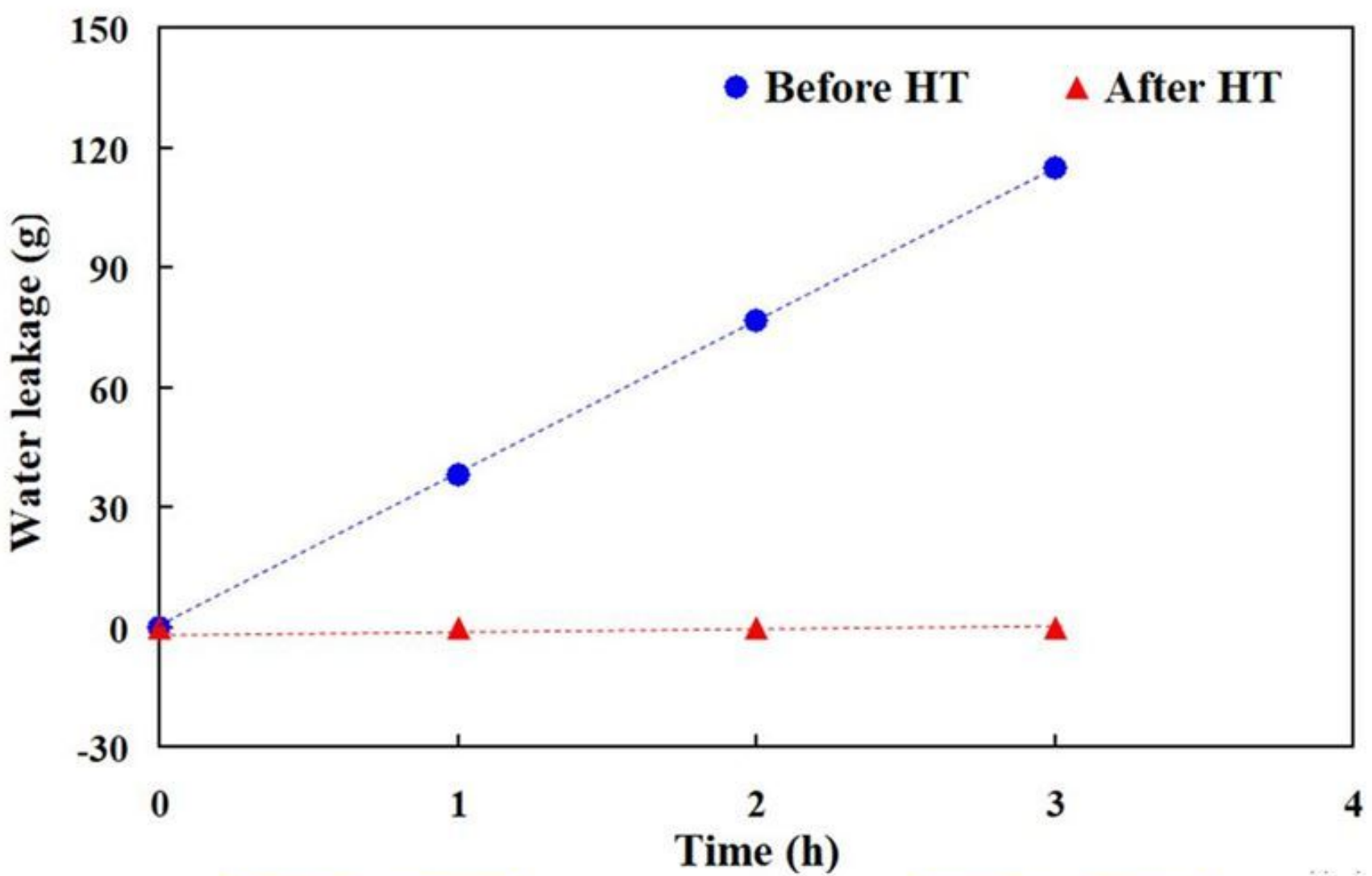

\section{Before HT}

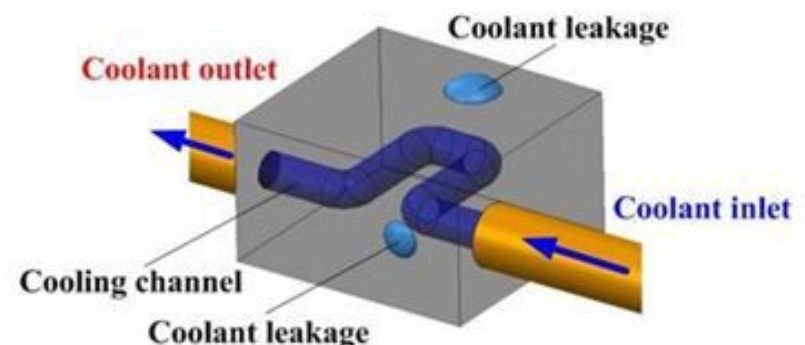

\section{After HT}
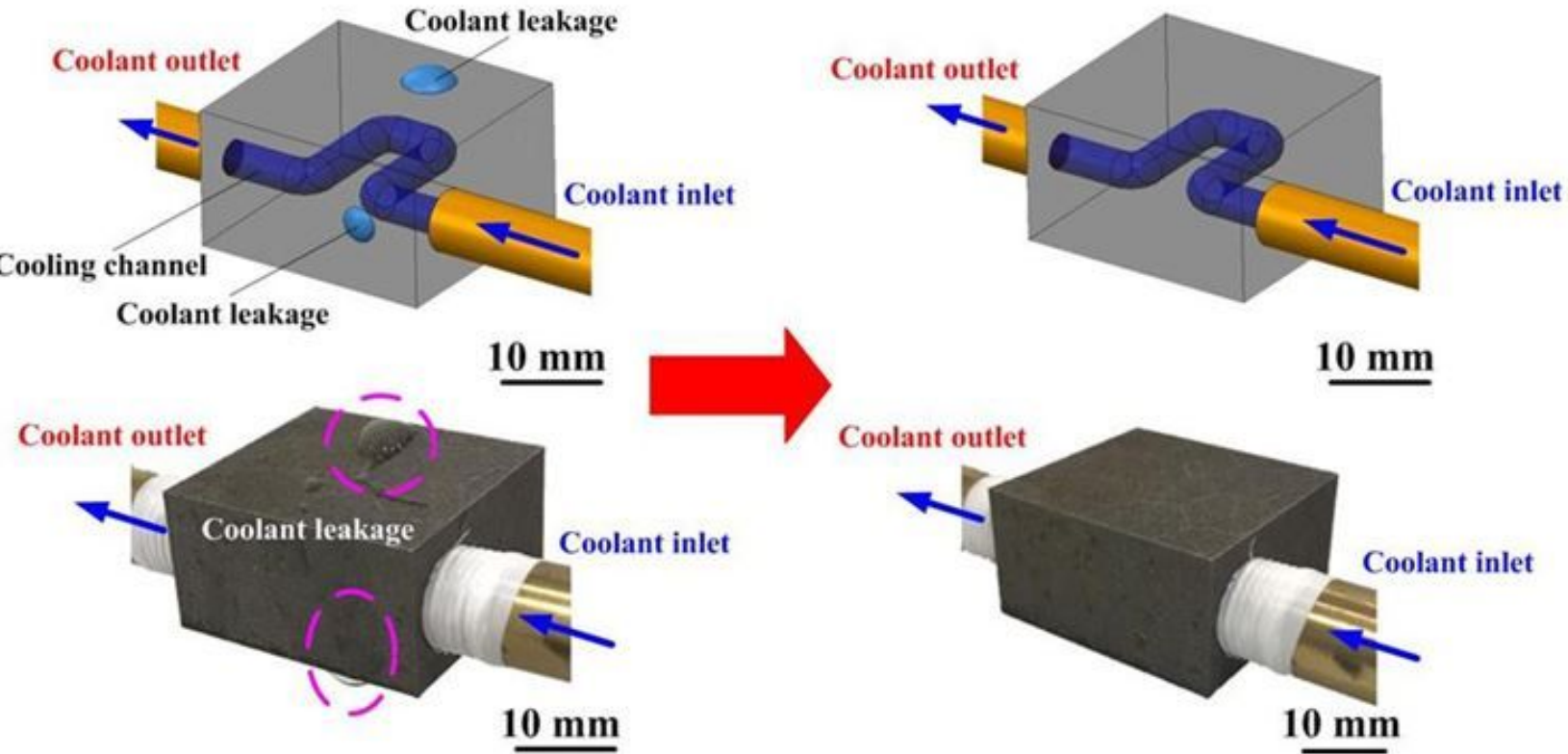

\section{$10 \mathrm{~mm}$}

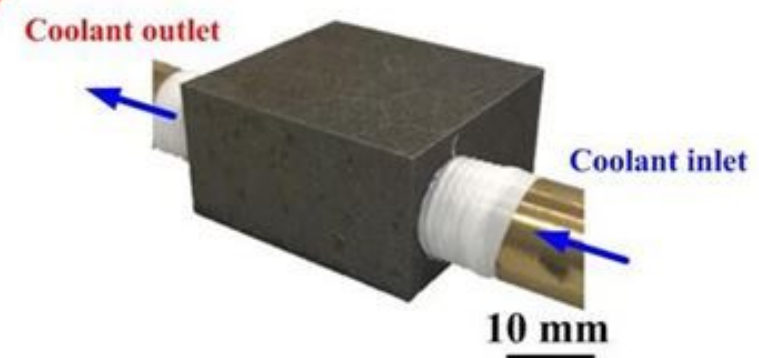

Figure 16

Coolant leakage test results before and after $\mathrm{HT}$ of the test injection mold with $\mathrm{CC}$ 

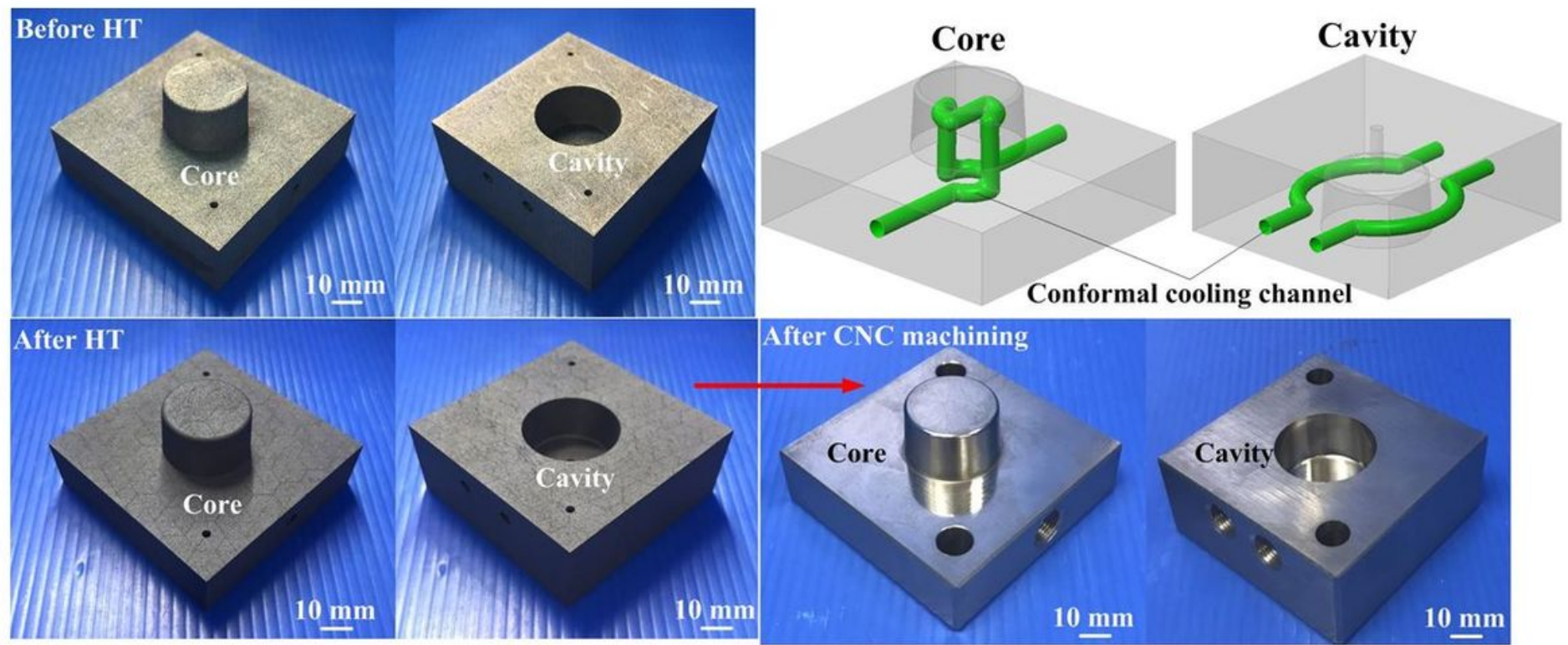

Figure 17

A set of injection mold for HT 


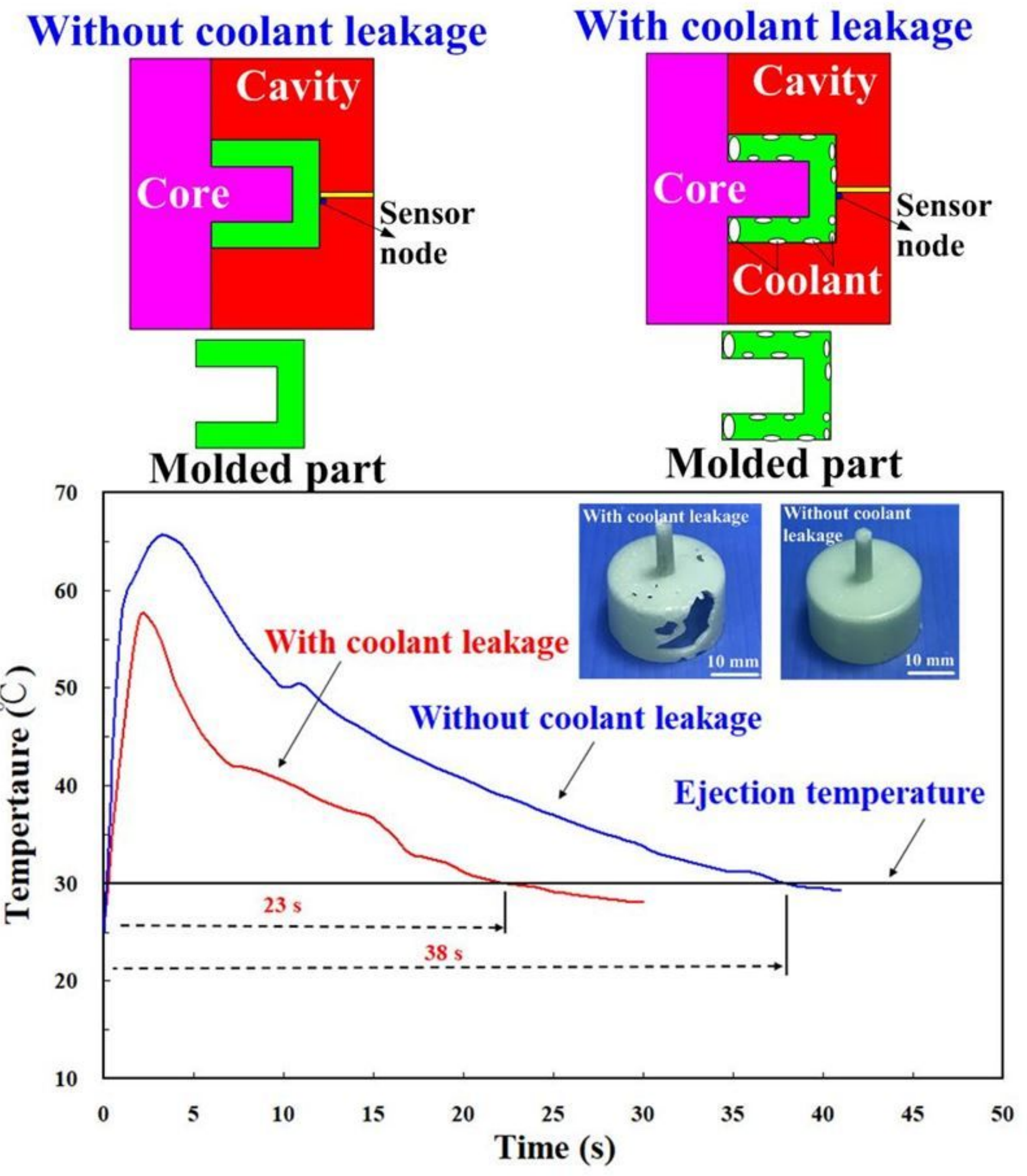

Figure 18

Part temperature as a function of the cooling time of the wax pattern after injection molding 


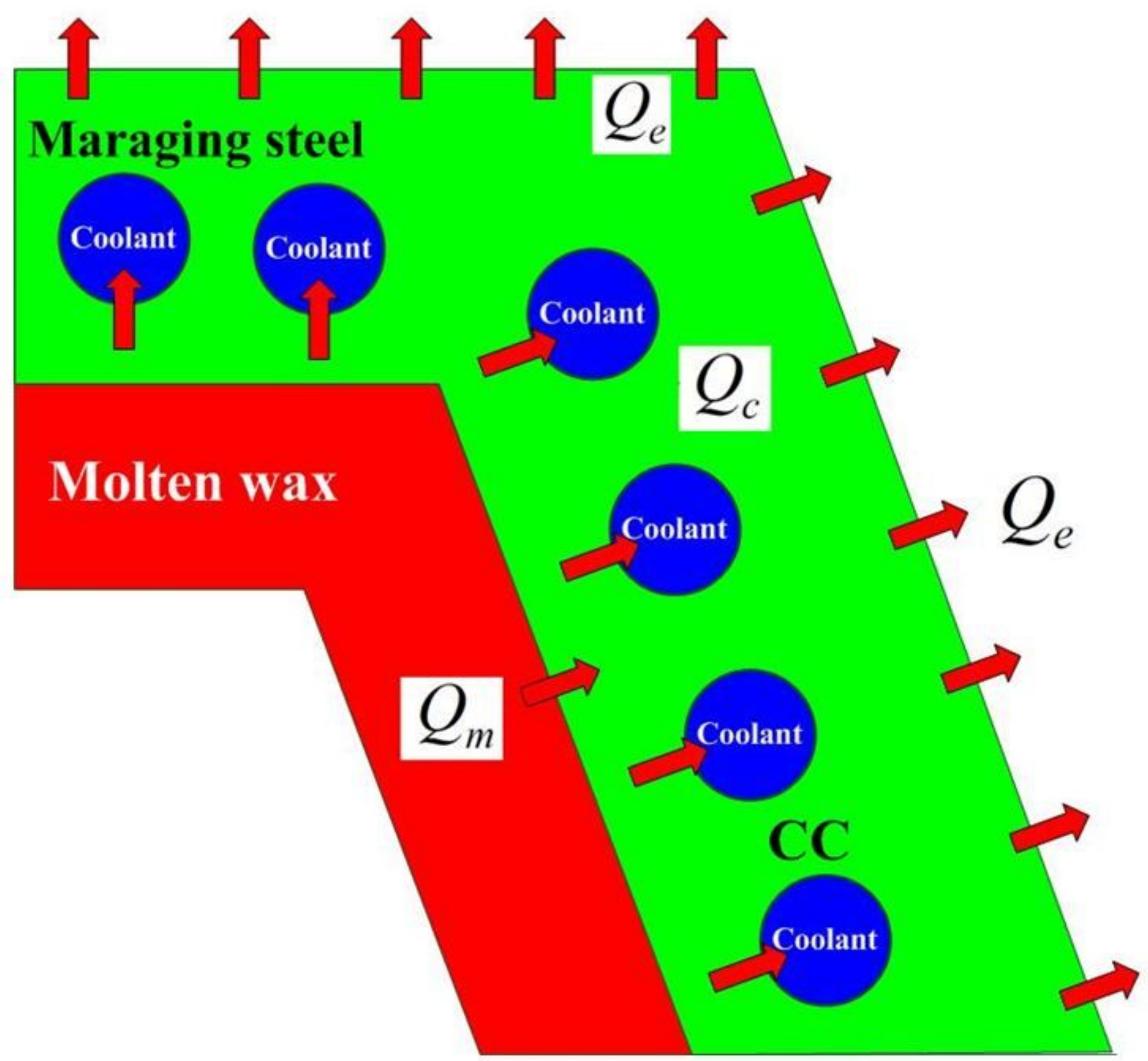

Figure 19

Schematic illustration of the heat fluxes during the cooling stage after low-pressure wax injection molding 


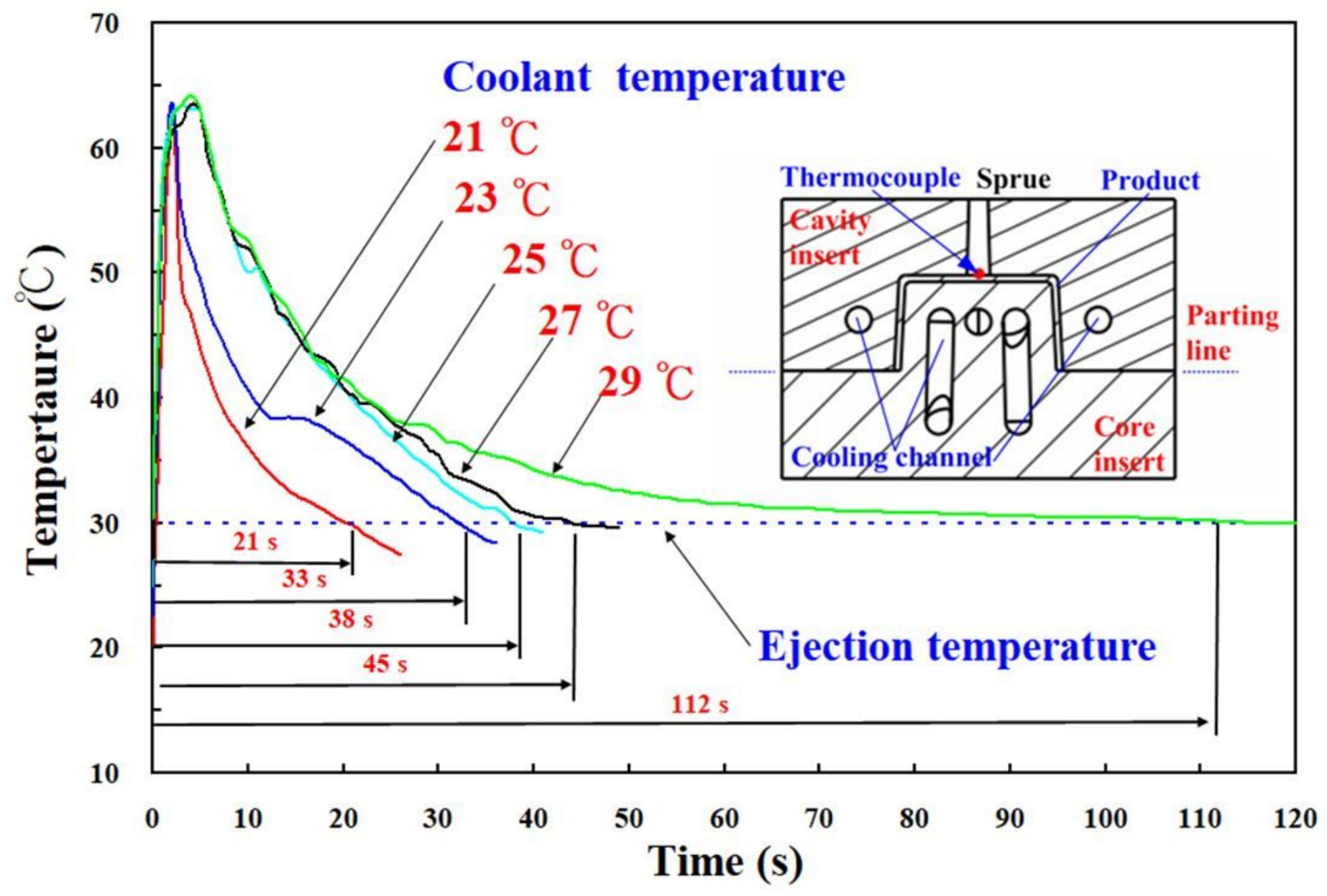

Figure 20

Part temperature as a function of the cooling time of the wax pattern for five different coolant temperatures 


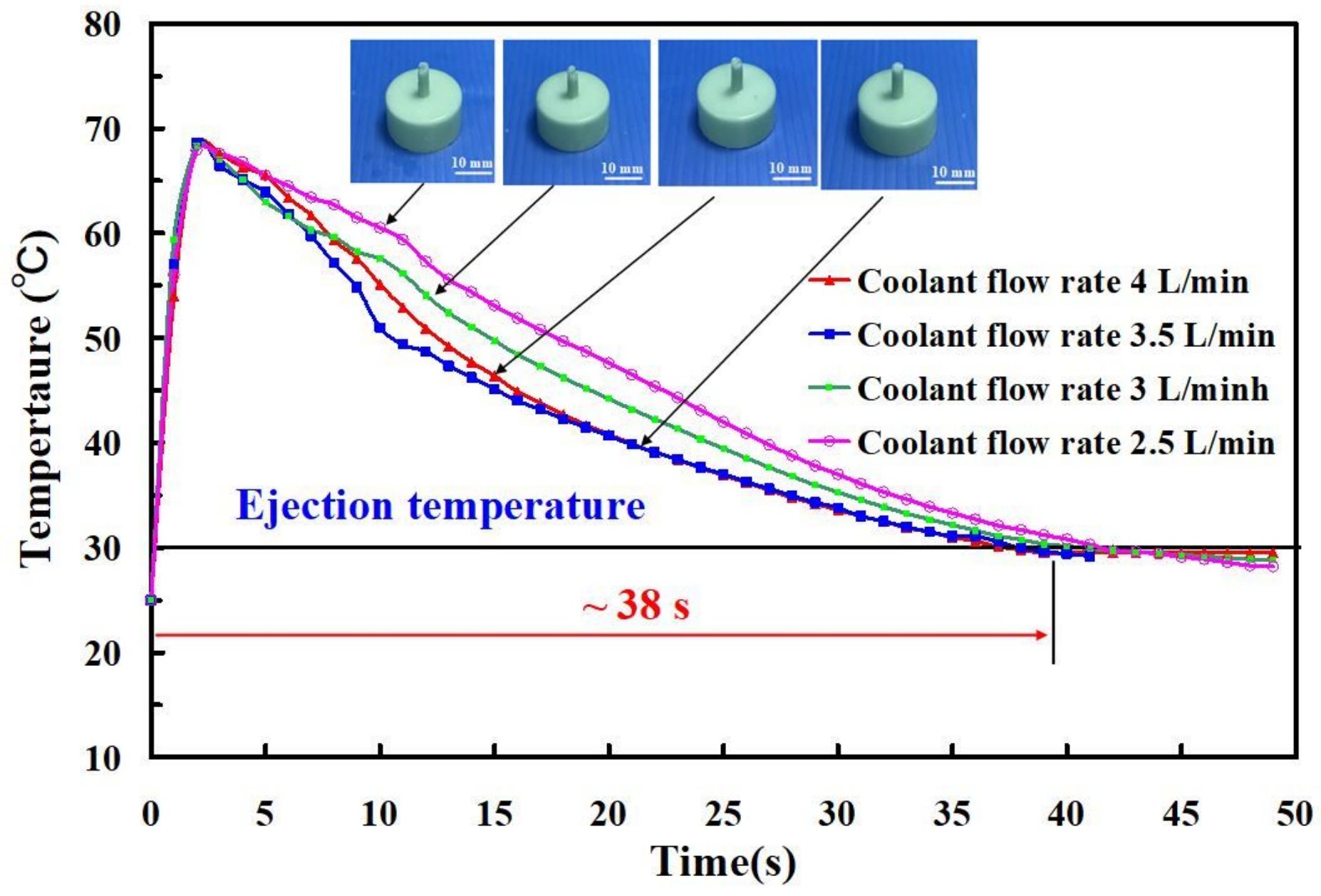

Figure 21

Part temperature as a function of the cooling time for four different coolant flow rates 


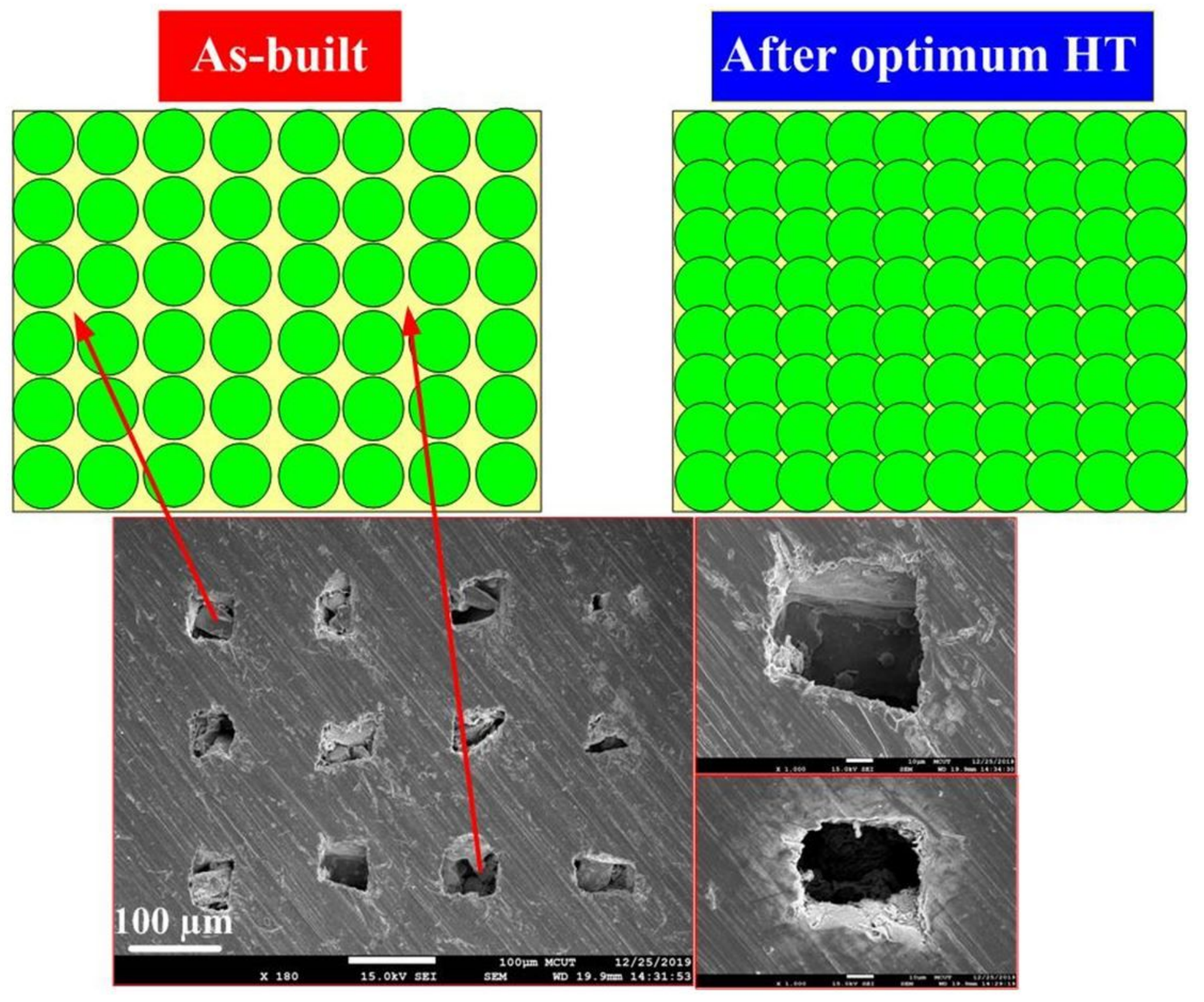

Figure 22

Microstructural developments after optimal HT 